\title{
High-fructose diet enhances cerebral neurodegenerative process; preventive effect of resveratrol. A nuclear magnetic resonance imaging and spectroscopy study on rat nutritional models
}

\author{
Marie-Christine Beauvieux ${ }^{\mathrm{a}, *}$, Claire Chambre $^{\mathrm{a}}$, Alan Stephant ${ }^{\mathrm{a}}$, Henri Gin $^{\mathrm{b}}$, \\ Anne-Karine Bouzier-Sore ${ }^{\mathrm{a}}$, Bader Chaarani ${ }^{\mathrm{a}}$, Gérard Raffard ${ }^{\mathrm{a}}$, Emmanuel Richard ${ }^{\mathrm{c}}$, Claire Castain ${ }^{\mathrm{d}}$, \\ Patrice Couzigou ${ }^{\mathrm{e}}$ and Jean-Louis Gallis ${ }^{\mathrm{a}}$ \\ ${ }^{a}$ Centre de Résonance Magnétique des Systèmes Biologiques, CNRS-Université Bordeaux Victor Segalen, \\ LabEx TRAIL-IBIO, rue Léo Saignat, Bordeaux Cedex, France \\ ${ }^{\mathrm{b}}$ Service de Nutrition et Diabétologie, Hôpital Haut-Lévêque, Avenue de Magellan, Pessac, France \\ ${ }^{\mathrm{c}}$ Laboratoire de Biochimie, Hôpital Pellegrin, Place Amélie Raba-Léon, Bordeaux, France \\ ${ }^{\mathrm{d}}$ Laboratoire de Pathologie, Hôpital Pellegrin, Place Amélie Raba-Léon, Bordeaux, France \\ e Service d'Hépatologie, Hôpital Haut-Lévêque, Avenue de Magellan, Pessac, France
}

\begin{abstract}
Insulin resistance (IR) could play a role in neurodegenerative diseases (ND). The high-fructose (HF) diet is an IR model in rats. The vitamin A-deprived (VAD) rat is known to develop large similarities with ND within only 14 weeks post-weaning. Since VAD symptoms are partly reversible and independent of any IR mechanism, this ND model was used to investigate (i) a potential additional effects of IR in a ND context, and (ii) a possible preventive strategy when resveratrol (RSV) is added to the diet.

Male Wistar rats were fed from weaning to 15-19 weeks: control, HF (60\%), VAD and a combination HF+VAD; some control, $\mathrm{VAD}$ and VAD + HF rats were force-fed with trans-RSV $(54 \mu \mathrm{g} / 100 \mathrm{~g}$ weight). In addition to assessing blood parameters (IR or inflammation), nuclear magnetic resonance (NMR) allowed both: (i) a longitudinal follow-up of brain anatomical (MRI) and early micro-structural changes (diffusion tensor imaging) and (ii) a metabolomic study of brain and liver ( ${ }^{1} \mathrm{H}$ HRMAS spectroscopy) at key points in the diets.

An early decrease ( $<6$ weeks) in fractional anisotropy in hippocampus was evidenced in VAD and preceded other impairments. HF diet induced biological IR from week 9 but brain metabolomic changes were already detected from week 5 . In contrast, no brain morphologic change was observed. VAD + HF diet impaired rat health, enhanced the retinolemia VAD-induced decrease and increased ventricular volume $v s$ both HF and VAD. Presence of RSV decreased IR, maintained retinol and attenuated the ventricular volume increase, probably via AMPKinase activation.
\end{abstract}

\footnotetext{
${ }^{*}$ Corresponding author: Marie-Christine Beauvieux, Centre de Résonance Magnétique des Systèmes Biologiques, Unité Mixte de Recherche 5536 Centre National de la Recherche Scientifique Université Bordeaux Segalen, LabEx TRAIL-IBIO, 146 rue Léo Saignat, F-33076 Bordeaux Cedex, France. Tel.: +33 5575712 95; Fax: +33 5575745 56; E-mail: marie-christine.beauvieux@chubordeaux.fr.
} 
Interestingly, these results allowed us to determine a sequence in brain impairments; first, micro structural changes, followed by metabolic disturbances and later on morphological modifications.

Keywords: Insulin resistance, fructose, vitamin A-deprived diet, nuclear magnetic resonance, brain, resveratrol

$\begin{array}{ll}\text { Abbreviations } \\ \text { AD } & \text { Alzheimer disease } \\ \text { AMPK } & \text { AMP-activated protein kinase } \\ \text { CNS } & \text { central nervous system } \\ \text { DTI } & \text { diffusion tensors imaging } \\ \text { FA } & \text { fractional anisotropy } \\ \text { FFA } & \text { free fatty acids } \\ \text { HF } & \text { high-fructose } \\ \text { HRMAS } & \text { high resolution magic angle spinning } \\ \text { IGF } & \text { insulin growth factor } \\ \text { IR } & \text { insulin resistance } \\ \text { MI } & \text { myo-inositol } \\ \text { MRI } & \text { magnetic resonance imaging } \\ \text { NMR } & \text { nuclear magnetic resonance } \\ \text { NAA } & \text { N-acetyl-aspartate } \\ \text { ROI } & \text { region of interest } \\ \text { RSV } & \text { resveratrol } \\ \text { SIRT1 } & \text { sirtuines1 } \\ \text { T2DM } & \text { type 2 diabetes mellitus } \\ \text { VAD } & \text { vitamin A deprived diet } \\ \text { VD } & \text { vascular dementia }\end{array}$

\section{Introduction}

Several diseases lead to dementia with varying symptoms and progression, the most common being Alzheimer's disease (AD) and vascular dementia (VD). The most widely established risk factor is age. A major economic and societal challenge will be to establish an early diagnosis in order to prevent and/or diminish the health and economic consequences, since dementia is projected to double every 20 years [1], representing a $£ 370$ billion sterling cost per year, mainly in the industrialized countries [2].

Most clinical investigations in neurodegenerative diseases (ND) are conducted in samples of patients already at an advanced stage of the disease. Research on earlier stages could provide more insight into the underlying physiopathology. In the rat, the model of vitamin A deprived diet (VAD) has been largely validated as a model of ND presenting all the sequences of a classical human ND such as AD, and offering the possibility to observe the onset of the process. Retinoids are required for long-term synaptic plasticity in the hippocampus, the key structure in memory processing [3]. Using NMR longitudinal studies, our team has demonstrated that in a rat model of VAD, a reduction in the bioavailability of retinoic acid (hypo expression of retinoid signaling) for only a short 10 -wk period has consequences on both the brain metabolic profile and brain anatomy, which is characteristic of ND [4]. These changes depicted earlier processes since at least 14-wk of VAD were required to affect the mRNA expression of some markers of amyloidogenesis by decreasing amyloid precursor protein expression and increasing $\beta$-secretase enzyme (cortex and hippocampus), other characteristics of ND [5]. VAD thus impaired spatial memory in rats [6]. After 1 year of this diet deficiency in adult rats, Corcoran et al. [7] evidenced a deposition of amyloid beta in the cerebral blood vessels. All the results reported above were obtained with induction of deprivation in just-weaning rats in order to avoid a liver accumulation of this lipophilic vitamin and to observe more rapid impairments. However, an interference with brain development cannot be excluded. A recent review clearly underlined the possible role of vitamin $\mathrm{A}$ in $\mathrm{AD}$ and suggested its key role in prevention and therapy, since low plasma and cerebrospinal fluid levels have been measured in AD patients [8]. The authors reported in vivo studies in which intraperitoneal injections of vitamin A decreased brain $\mathrm{A} \beta$ deposition and tau phosphorylation in transgenic mouse models of $\mathrm{AD}$, thereby attenuating neuronal degeneration and improving spatial learning and memory.

Numerous studies have examined the implication of insulin resistance (IR) in ND. Epidemiological studies strongly suggest that metabolic defects such as type 2 diabetes mellitus (T2DM), obesity, hypertension and dyslipidemia, correlate with the functional alterations associated with brain aging. Population-based longitudinal studies have shown that the risk of VD and $\mathrm{AD}$ is increased in patients with T2DM [9]. Moreover, the glycemic index of the evening meal was associated with memory performance the next day [10]. Recent work pointed out that IR may suggest co morbid metabolic disorders and thereby increase dementia risk [11, 12]. Research on the functions and signaling 
pathways of insulin has traditionally focused on peripheral tissues such as muscle, fat and liver, while the brain was commonly believed to be insensitive to the effects of this hormone secreted by pancreatic beta cells. Insulin crosses the blood-brain barrier using a saturable transporter altered by physiological and pathological factors including hyperglycemia and the diabetic state [13]. Whereas the density of brain insulin receptor decreases with age, insulin growth-factor-1 (IGF-1) receptor increases, suggesting that specific insulin-mediated signals are involved in aging and possibly in cognitive decline [14]. Brain insulin signaling is particularly important for learning and memory [15].

Consuming large amounts of fructose can induce a complete metabolic syndrome in rodents characterized by a profound metabolic dyslipidemia [16], and this high-fructose (HF) model is characterized by the absence of obesity (in contrast to high-fat rat). In rats, chronically HF diet may induce hepatic IR followed 4 or 5 wks after by extrahepatic IR [17] and led to hippocampus IR in the hamster [18]. The mechanistic connection between fructose-induced IR and cognitive impairment is suggested by impaired spatial learning and ability tasks in fructose rats [19] as well as by a decrease in neuronal insulin signaling pathways in the cerebral cortex and hippocampus [20].

Our main goal was to study the impact of IR on the development of the ND process. To our knowledge, this has never been performed by using only nutritional models to describe the earliest steps. For this purpose, we have associated a fructose diet (generating IR) to a VAD diet (generating ND) in rats. An additional goal consisted in testing the effects of a preventive nutritional strategy.

One of the major advantages of the VAD model is the partial reversibility of metabolic [6], protein expression [21] and spatial memory [22] impairments. Reversibility is not possible with transgenic animals, so the potential preventive or therapeutic effects of nutritional molecules could not be studied, whereas it will be possible in our nutritional models.

Among the preventive strategies, the use of resveratrol (RSV), a natural polyphenol in grapes and red wine, is a possible candidate activating sirtuins 1 (SIRT1). In mammalian, SIRT1 activators protect against axonal degeneration and microglia-mediated amyloid $\beta$ toxicity, suggesting their potential therapeutic value in ND [23], as recently reviewed [24]. Moreover, SIRT1 increases both pancreatic insulin secretion stimulated by glucose [25] and sensitivity to insulin receptors [26]. The dual interest of studying the action of RSV during a fructose diet is underlined by Ramadori et al. [27] when they pointed out a key role for the CNS in mediating the anti-diabetic actions of RSV. Indeed, a long-term intracerebroventricular infusion of RSV normalizes hyperglycemia and greatly improves hyperinsulinemia in diet-induced obese and diabetic mice. Hippocampus, cortex and cerebellum neuroprotection was also reported when streptozotocin-induced diabetic rats were treated by RSV [28]. When orally administered in mice, RSV was detected in the brain where it activates AMPK and reduces cerebral $A \beta$ levels and deposition in the cortex, suggesting that (i) this molecule crosses the blood-brain barrier and (ii) RSV appears as a potential therapeutic against ND by modulating energy metabolism [29].

This is the first study using rat nutritional models to describe the gradual onset of metabolic and neuropathologic disorders and to evaluate the impact of IR on ND. Nuclear magnetic resonance (NMR) (imaging and spectroscopy) was used to study both anatomic and metabolic markers. The association of these two NMR approaches allowed us to investigate the time sequence of events that could highlight the physiopathological process. There were two goals: (i) to assess the impact of a supplementary high-fructose diet (that leads to IR) in rats undergoing a Vitamin A-deprived diet (that leads to ND symptoms); (ii) to estimate the preventive effect of oral RSV.

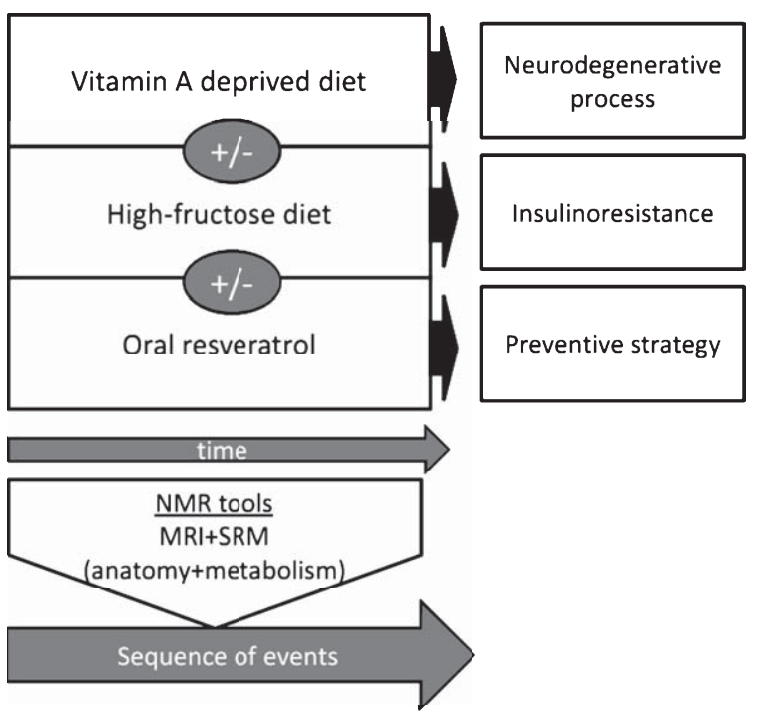


Table 1

Formulation of specific diets. ${ }^{1}$ Control diet was the same as VAD one except for presence of vitamin A 8000 UI. For the VAD + HF diet, the formulation contained fructose but no vitamin A

\begin{tabular}{|c|c|c|}
\hline Ingredient (\%) & Vitamin-A free diet & High-fructose diet \\
\hline Casein & 23 (free vitamin A) & 23 (normal) \\
\hline $\begin{array}{l}\text { Monohydrated } \\
\text { Dextrose }\end{array}$ & 40.16 & - \\
\hline Cellulose & 6.77 & 6.77 \\
\hline Corn starch & 20 & - \\
\hline Fructose & - & 57.23 \\
\hline Stearic acid & 3 & 3 \\
\hline Glycerol & 1 & 1 \\
\hline $\begin{array}{l}\text { Oils (i.e., evening } \\
\text { primrose) }\end{array}$ & 1 & 1 \\
\hline \multicolumn{3}{|l|}{ Vitam mix $^{2}$} \\
\hline Mineral $\operatorname{mix}^{3}$ & $\begin{array}{c}5.07 \\
(\text { free vitamin } \mathrm{A})\end{array}$ & $\begin{array}{c}5.07(\text { vitamin A500 } \\
\left.0.0017^{4}\right)\end{array}$ \\
\hline
\end{tabular}

${ }^{1}$ Diets from SAFE (France) stored in sealed bags at $4{ }^{\circ} \mathrm{C}$. ${ }^{2}$ Composition of mineral mix: SAFE mineral 205B. ${ }^{3}$ Composition of vitamin mix: SAFE premix vitamin $200 .{ }^{4}$ Vitamin A 8000 UI.

\section{Material and methods}

\subsection{Animals and diets}

Just weaning ( 3 weeks old, initial weight $50 \mathrm{~g}$ ) Wistar male rats were purchased from Janvier (France). Owing to the VAD model, the diets were begun at weaning in order to avoid hepatic accumulation of lipophilic vitamin A [5]. Rats were housed in cages in a room with a constant airflow system, controlled temperature $\left(21-23^{\circ} \mathrm{C}\right)$ and a 12-h-light/-dark system. They had unrestricted access to water. All rats were fed with $10 \mathrm{~g}$ isocaloric diets/100 $\mathrm{g}$ body weight per day. The VAD, HF and VAD-HF diets were purchased from SAFE (Scientific Animal Food and Engineering, Augis France) and were stored in sealed bags at $4{ }^{\circ} \mathrm{C}$. For composition of the diets, see Table 1.

The protocol included 4 experimental groups, for each the number of rats at the beginning of the protocol is specified:

Group 1: control group fed with standard chow laboratory pellets $(n=18)$,

Group 2: VAD group receiving a vitamin A-depleted food $(n=18)$,

Group 3: HF group fed with diet containing $60 \%$ fructose $(600 \mathrm{~g} / \mathrm{kg}$ dry weight $)(n=16)$,

Group 4: VAD-HF group combining diets of groups (2) and (3), which was fed with VAD diet

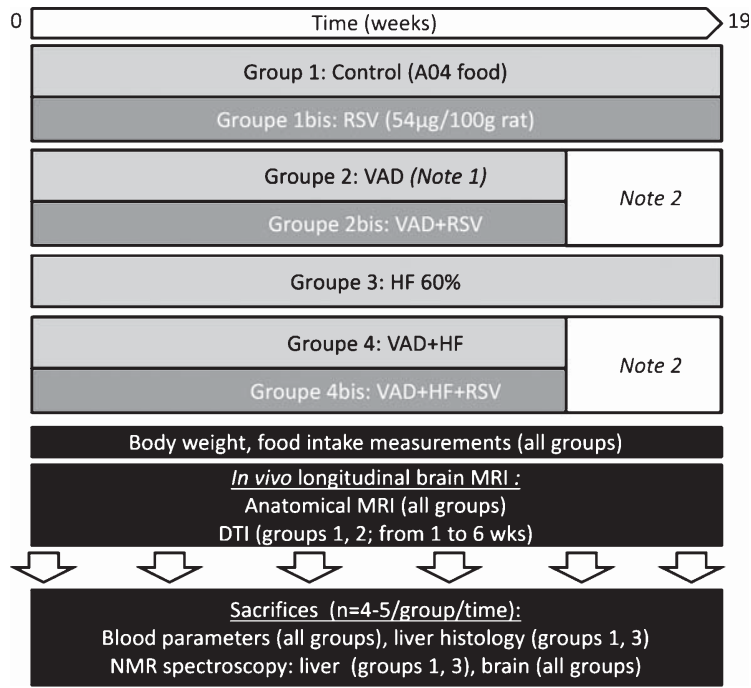

Scheme 1. Design of study presenting different groups of rats receiving specific diets and visualization of analysis over time. At the beginning of the protocols, the number of rats was as follows in each group: Control (group 1) $n=18$, RSV alone (group 2) $n=14$, $\mathrm{VAD}$ (group 2) $n=18$, VAD $+\mathrm{RSV}$ (group 2b) $n=15$, HF (group 3) $n=16, \mathrm{VAD}+\mathrm{HF}$ (group 4) $n=17, \mathrm{VAD}+\mathrm{HF}+\mathrm{RSV}$ (group 4b) $n=12$. Note 1 : in VAD condition, 4 additional rats were re-fed with normal diet to observe clinical reversibility of symptoms. Note 2: in groups receiving $\mathrm{VAD}$, the life span was shorter due to deterioration of health.

where dextrose and starch was replaced by fructose in order to study the incidence of IR on neurodegenerative parameters $(n=17)$.

Three other groups were dedicated to the study of the effect of RSV: control (group 1bis), VAD (group 2bis) and VAD + HF (group 4bis). Rats were force-fed with trans-RSV ( $1.8 \mathrm{ml} / 100 \mathrm{~g}$ body weight twice a week at the threshold solubility of $30 \mathrm{mg} / \mathrm{L}$ of water, corresponding to $54 \mu \mathrm{g}$ trans-RSV/100 g rat, Sigma) : RSV alone (group 1bis), $n=14$, VAD+RSV (group 2bis), $n=15$ and VAD $+\mathrm{HF}+\mathrm{RSV}$ (group 4bis), $n=12$. The $\mathrm{HF}$ group was not supplemented because the study focused first on the ND process, so RSV was mainly tested in VAD groups. Moreover, the literature largely highlights a positive effect of RSV on insulin sensitivity; knowledge to date is presented in the discussion section.

The diets were applied 19-20 wks post-weaning except in VAD and VAD + HF groups, in which VAD rats are known to stop gaining weight and to develop clinical symptoms leading to early death (around 15 
wks) [5]. Rats were weighed every 2 days and food intake was monitored.

The laboratory is licensed for animal experiments (French Agriculture Department). The protocol complied with 1999 UFAW guidelines [30], was carried out in accordance with EC Directive 86/609/EEC for animal experiments and was approved by the Regional Ethics Committee for Animal Experiments in our University.

\subsection{Experimental protocol}

Rats were submitted to two types of experiments as shown in Scheme 1.

\subsubsection{In vivo longitudinal magnetic resonance imaging}

Longitudinal in vivo magnetic resonance imaging (MRI) was performed. Each rat was its own control and was followed up several times throughout its diet. This study mainly concerned anatomical measurements (total brain, ventricles and hippocampus volumes) and was performed in all groups of rats. An additional diffusion tensor imaging was performed for rats in groups 1 (control) and 2 (VAD) only, at the beginning of the diet.

2.2.1.1. Anatomic MRI. In vivo NMR brain imaging was performed each wk between wk 1 and 6 , then at 9, 12-14 and $19 \mathrm{wk}$ on a horizontal 4.7T Biospec 47/50 system (Bruker, Ettlingen, Germany) equipped with a $12-\mathrm{cm}$ gradient system $(850 \mathrm{mT} / \mathrm{m})$ (the last point was excluded in rats receiving VAD owing to their shorter life-span). The same rats were monitored repeatedly over time allowing a longitudinal follow-up ( $n=4-5$ for the same diet). Rats were anaesthetized with isoflurane $1.5 \%$. The dose was monitored from outside the magnet and gas was delivered through an extension line $(1 \mathrm{~L} / \mathrm{min})$. A follow-up of physiological parameters was performed (PC-SAM 32 ) in order to synchronize the acquisition with respiratory motions. Coronal T2-weighted images of the brain were obtained using a RARE sequence (RARE factor $=16, \mathrm{TE}=69 \mathrm{~ms}, \mathrm{TR}=5785 \mathrm{~ms}, 24$ scans $)$ with spatial resolution $1.8 \times 1.8 \mathrm{~cm}$ and consecutive $1-\mathrm{mm}$ slices. 3D images were obtained with a Flash 3D sequence $(\mathrm{TE}=4 \mathrm{~ms}, \mathrm{TR}=10 \mathrm{~ms}, 8$ scans $)$. Total brain, ventricular and hippocampal volumes were evaluated with Amira® 6.0 software from MRI images, area being outlined manually, with a reproducibility verification performed as explained in the following section.

2.2.1.2. In vivo brain diffusion MRI. This section presents a preliminary study performed only in the VAD alone (group 2) vs control (group 1), VAD being the validated model of ND. DTI was performed once a week only at wk 2, 3, 4 and 6 following the beginning of the diets. Indeed, the focus on this early period was highly linked to our goal, i.e. to evidence potential water diffusivity changes that could occur earlier than all the other changes (metabolic and/or macro anatomical ones). Diffusion tensor images (21 axial slices of $0.6 \mathrm{~mm}$, b-value $1000 \mathrm{~s} / \mathrm{mm}^{2} ; 30$ diffusion directions; resolution: $0.312 \times 0.312 \times 1 \mathrm{~mm}^{3}$ ) were acquired at 4.7T on a Biospec $47 / 50$ equipped with a $6-\mathrm{cm}$ gradient system $(1000 \mathrm{mT} / \mathrm{m}, \Delta=20 \mathrm{~ms}, \delta=4 \mathrm{~ms})$. Both coronal morphological MRI and DTI were performed on the same rat, which allowed us the determination of the correct location of brain structures for DTI analysis. For this morphological MRI, same sequence than those presented in the previous section was used, in coronal axis. Due to the high sensitivity of diffusion imaging to motion artifacts, DTI was synchronized with respiration. Different DTI parameters were computed using region of interests (ROIs) manually defined on diffusion images. Measurements were performed on ROIs manually defined with ParaVision software (Bruker). Fraction anisotropy (FA) and mean diffusivity (MD in $\mathrm{mm}^{2} / \mathrm{s}$ ) were measured on different brain structures (cortex, hippocampus and striatum).

For all region-of-interest analyses, voxels were selected from the FA and MD maps by 2 coinvestigators blinded to experimental design and treatment, such as for manual selection of anatomical MRI area. Interobserver and intraobserver error were expressed by calculating the $\mathrm{CV}(\mathrm{CV}=\mathrm{SD} /$ mean $)$ after repeating measurements. For intraobserver reproducibility, measurements were done 3 times for each rat. Intraobserver comparison in FA and MD measurements did not reveal statistical difference $(\mathrm{CV}<3 \%)$. For interobserver measurements, $\mathrm{CV}$ was less than $4 \%$. A good reproducibility and no DTI distorsion were expected according to the absence of movements since rats were anaesthetized, and to the large resolution obtained on a $4.7 \mathrm{~T}$ magnet.

\subsubsection{Ex vivo analysis}

Some rats in each group were sacrificed at different times of the protocol. Several parameters were 


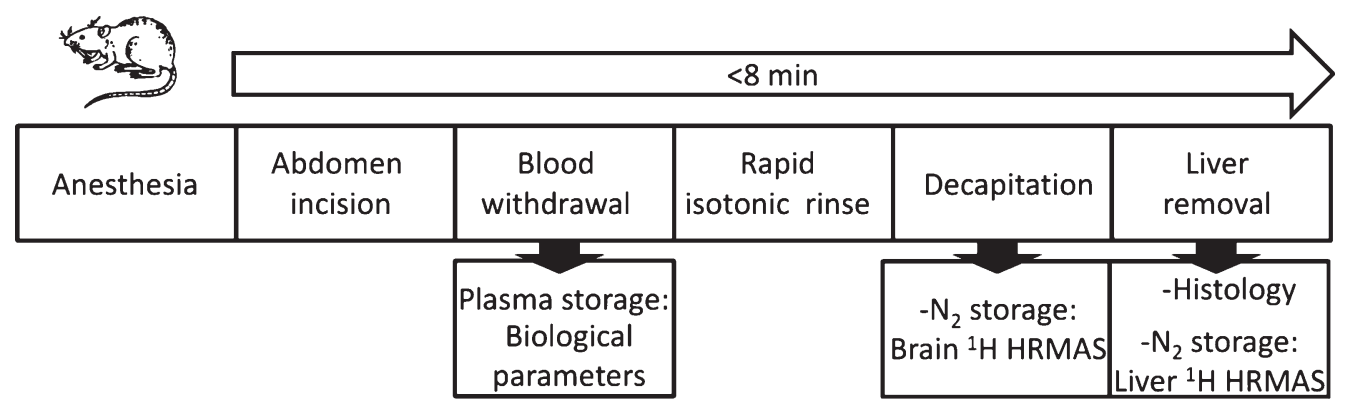

measured: (i) blood biological parameters in all rats, (ii) histological and/or NMR spectroscopy analysis of liver in HF (group 3) in order to validate the IR diet model; (iii) brain metabolites in all groups, using NMR spectroscopy ( ${ }^{1} \mathrm{H}$ HRMAS) in various structures (cortex, hippocampus, striatum). For each time point, the results are presented at the end of the diet period. For example, results at wk 5 post-weaning mean that the diet had already lasted 4 entire wks.

2.2.2.1. Sacrifice. At different times (generally 5th, 9th, 12-14th wks of the diets), some rats were anesthetized with an intraperitoneal injection of sodium pentobarbital ( $1 \mathrm{ml} / \mathrm{kg}$ of body weight) and kept under analgesia with intramuscular injection of xylazine ( $5 \mathrm{mg} / \mathrm{kg}$ of body weight). There were at least four rats in each experimental condition and at each time of sacrifice. Abdomen was incised in order to (i) collect blood, (ii) eliminate residual blood by a rapid isotonic rinse via the portal vein, (iii) remove the head to freeze the brain for further NMR spectroscopic analysis and (iv) remove the liver for both histological and/or NMR spectroscopic analysis (this one on frozen tissue). Details of these procedures are described hereafter.

2.2.2.2. Blood parameters. Total blood was collected on heparin in the inferior vena cava in order to measure blood parameters such as glycemia and insulinemia (Diasorin immunoassay, Antony, France). Glucose, proteins, albumin, triglycerides and total cholesterol were measured spectrophotometrically on a multiparametric analyzer (Beckman Coulter Olympus AU2700, Villepinte, France). Retinol and $\alpha$-tocopherol were measured by high-performance liquid chromatography according to the method of Leclercq and BourgeayCausse [31].

2.2.2.3. ${ }^{1} H$ HRMAS spectroscopy on tissues. Just after blood collection, liver was perfused via the por- tal vein with isotonic Krebs-Henseleit buffer $\left(37^{\circ} \mathrm{C}\right.$, $\mathrm{O}_{2}-\mathrm{CO}_{2} 95: 5,5 \mathrm{ml} / \mathrm{ming}^{-1}$ ) in order to avoid blood contamination in NMR signals. It was removed, rapidly weighed and freeze-clamped in aluminum tongs in liquid nitrogen and kept at $-80^{\circ} \mathrm{C}$. Liver was further analyzed by NMR in control (group 1) and HF (group 3) rats. Then rat was immediately sacrificed with a scientific guillotine and the head put in liquid nitrogen. The differentiated brain structures, cortex, hippocampus and striatum were extracted and kept at $-80^{\circ} \mathrm{C}$ to be analyzed in all groups of rats. Proton HRMAS NMR spectroscopy using an Avance500 Bruker operating at 11.7T was performed on $20 \mathrm{mg}$ samples of each tissue maintained at $273^{\circ} \mathrm{K}$ throughout the experiment. Each sample was placed in a $50 \mu$ l insert (Bruker Biospin Ltd, Germany), and the total relaxed spectrum with suppression of water resonance was analyzed ( size $32 \mathrm{~K}, 16$ scans, total acquisition time $=6 \mathrm{~min}$, relaxation time $6 \mathrm{~s}$, total spin-echo delay $=30 \mathrm{~ms}$ ). A Carr-Purcell-Meiboom-Gill sequence was applied to eliminate the contribution of macromolecules in the baseline value. Absolute quantification was made by means of external fumarate (disodium salt) in $\mathrm{D}_{2} \mathrm{O}$ $(20 \mu \mathrm{l}, 50 \mathrm{mmol} / \mathrm{L})$. By spinning samples to the magic angle $\left(\theta=54.7^{\circ}\right)$, line-broadening processes such as dipole-dipole couplings, chemical shift anisotropy and magnetic susceptibility changes are significantly reduced in order to obtain a high resolution spectrum in 6 min. Most of the NMR spectroscopic studies are usually performed in vitro or ex vivo on perchloric acid extracts. Unfortunately, the metabolic extraction process complicates interpretation of results. A metabolite's concentration in an extract reflects its relative solubility in the extraction medium as well as its cellular contribution. The value of HRMAS is that it directly uses a small piece of tissue without any chemical extraction, thus conserving all the metabolic information. 
2.2.2.4. Histology. Just before freeze-clamping of the liver, a piece of the right lobe of livers in the control and $\mathrm{HF}$ rats (groups 1 and 3) was fixed in $10 \%$ Formalin and stained with haematoxylin and eosin (H\&E) (Masson's trichrome stain). Histology was read by a single independent pathologist blinded to the experimental design and treatment. The histological study focused on the presence and quantity of three criteria: steatosis, inflammation around it, and fibrosis.

\subsection{Statistical analysis}

Statistical comparison between groups and treatments was performed with non parametric tests such as Mann-Whitney U test for 2 independent groups, ANOVA with Student-Newman-Keuls test for 3 and more independent groups. A $p$-value of $<0.05$ was considered statistically significant. Data are presented as mean \pm SEM.

\section{Results}

\subsection{Body weight and morphological observations}

Control rats had regular growth from weaning until a plateau near wk 10 post-weaning around $400 \mathrm{~g}$ (Fig. 1). $\mathrm{HF}$ rats had a weight gain similar to controls until wk 8 . It was $17 \%$ higher at the end of the protocol whereas the food intake remained stable (Fig. 1A). VAD arrested weight gain from wk 5, leading to a plateau near a maximum value of $340 \mathrm{~g}$ followed by a weight decrease from wk 11. General health status deteriorated. The rats developed cutaneous lesions especially in the periorbital and eyelid skin. These lesions were characterized by erythema, partial alopecia, and crusting [32] and the animals had died by wk 15 weighing near $260 \mathrm{~g}$ and with gait disturbances. The combined VAD $+\mathrm{HF}$ diet induced a rapid arrest in weight gain (4.5 wks) followed by a decrease to a final value near $225 \mathrm{~g}$ between wk 10 and 11 (Fig. 1A), with major impairment in general health. We previously demonstrated that retinoic acid treatment restored some parameters in the VAD group [6]. It is important to demonstrate the reversibility of deprivation in order to study the effects of preventive and/or curative strategies. Here we added some results by reintroducing normal food containing retinol in some rats $(n=4)$ dedicated to this goal. This led to weight recovery similar to that of controls within 3 wks (Fig. 1A). In all diets concerned, RSV present
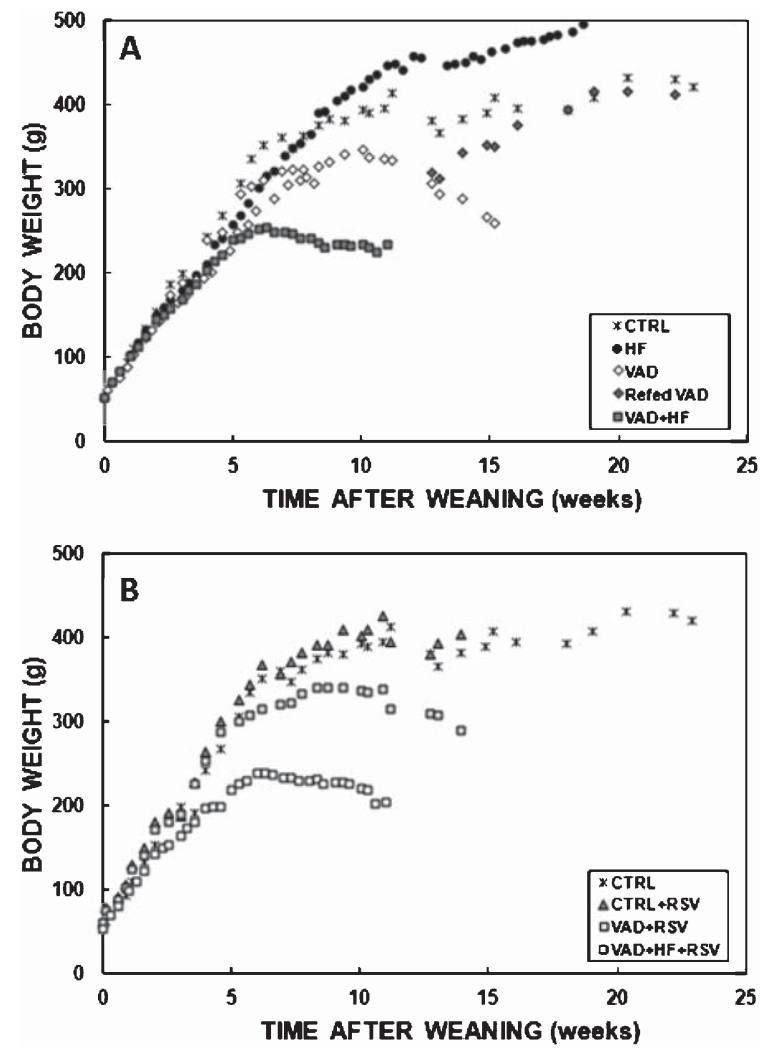

Fig. 1. Effects of different diets on body weight, values are means, $n=12-18$ at the onset of the protocol, this number decreasing gradually according to sacrifice times. Only control group was measured until 23rd wk to evidence plateau.

from the beginning of the diets induced no change in the weight curves of the rats (Fig. 1B).

In $\mathrm{HF}$ rats, the viscerosomatic adiposity index increased with an increase in both retroperitoneal, and epididymal fat deposits vs controls (Fig. 2).

\subsection{Blood parameters}

Plasma retinol concentrations diminished dramatically and rapidly in VAD rats (group 2) to reach zero at 12 wks of diet, a value significantly different from that at wk $5(p=0.01)$ (Table 2). Reintroduction of vitamin A-containing diet at 13 wks restored the retinol level close to that of controls (not shown). Whereas HF (group 3) maintained retinolemia near control values throughout the protocol (with a tendency to increase), the combination of IR status with VAD (group 4) enhanced the retinol VAD decrease by 


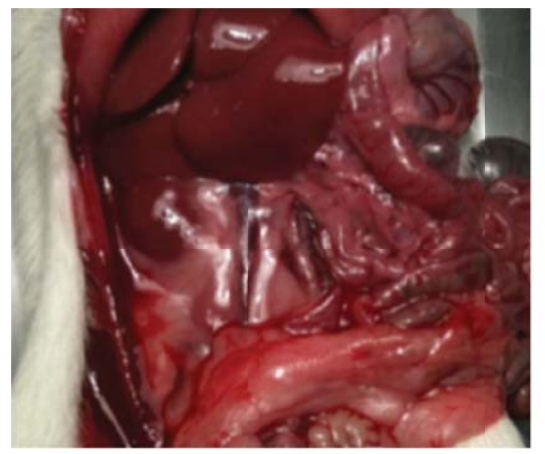

CONTROL

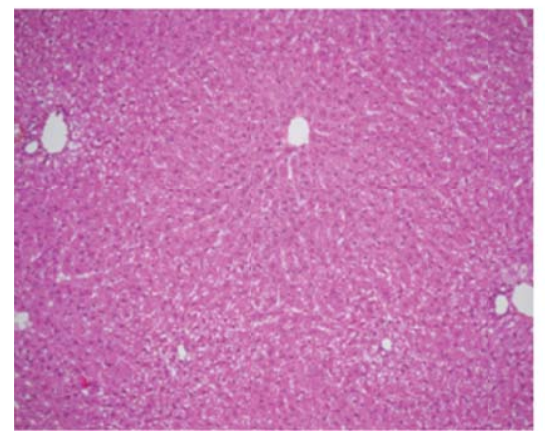

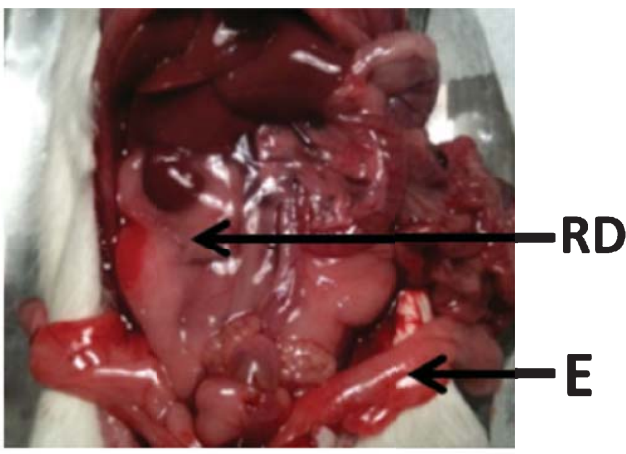

$\mathrm{HF}$

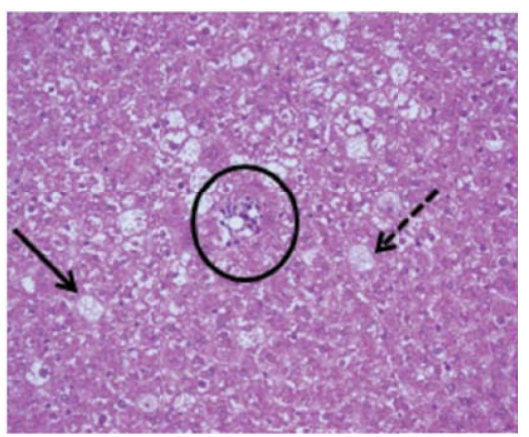

Fig. 2. Typical abdominal fat deposits and liver histology after 9 wks of high-fructose diet (group 3). HES stain, x200. RD: retroperitoneal fat deposit; E: epididymes. The circle: inflammatory cells, the full arrow: macrosteatosis, discontinued arrow: microsteatosis.

Table 2

Blood biological parameters according to different diets. $m \pm$ SEM. $n=4-5$ according to time of sacrifice

\begin{tabular}{|c|c|c|c|}
\hline & 5 week diet & 9 week diet & 12-14 week diet \\
\hline \multicolumn{4}{|l|}{ Retinol $(\mu \mathrm{mol} / \mathrm{l})$} \\
\hline Control & $1.33 \pm 0.07$ & $1.12 \pm 0.01$ & $1.25 \pm 0.04$ \\
\hline VAD & $0.44 \pm 0.06$ & $0.014 \pm 0.006$ & 0 \\
\hline & $p=0.01 v s$ control & $p=0.0002 v s$ control & \\
\hline $\mathrm{HF}$ & $1.61 \pm 0.22$ & $1.42 \pm 0.23$ & $1.38 \pm 0.72$ \\
\hline $\mathrm{VAD}+\mathrm{HF}$ & $\begin{array}{c}0.23 \pm 0.05 \\
p=0.05 v s \mathrm{VAD}\end{array}$ & $\begin{array}{c}0.008 \pm 0.003 \\
p=\mathrm{NS} v s \mathrm{VAD}\end{array}$ & ND \\
\hline $\mathrm{VAD}+\mathrm{HF}+\mathrm{RSV}$ & $0.34 \pm 0.15$ & $\begin{array}{c}0.025 \pm 0.003 \\
p=0.012 \text { vs } \mathrm{VAD}+\mathrm{HF}\end{array}$ & ND \\
\hline \multicolumn{4}{|c|}{$\alpha$-tocopherol $(\mu \mathrm{mol} / \mathrm{L})$} \\
\hline Control & $11.04 \pm 0.32$ & $11.34 \pm 0.015$ & ND \\
\hline VAD & $\begin{array}{c}18.39 \pm 0.80 \\
p=0.02 v s \text { control }\end{array}$ & $\begin{array}{c}25.43 \pm 1.85 \\
p=0.02 v s \text { control }\end{array}$ & ND \\
\hline $\mathrm{HF}$ & $\begin{array}{c}22.12 \pm 2.12 \\
p=0.03 v s \text { control }\end{array}$ & $\begin{aligned} & 29.39 \pm 2.39 \\
p= & 0.008 v s \text { control }\end{aligned}$ & $32.32 \pm 5.7$ \\
\hline $\mathrm{VAD}+\mathrm{HF}$ & $\begin{aligned} & 34.37 \pm 3.10 \\
p= & 0.008 v s \text { control }\end{aligned}$ & $\begin{array}{c}30.39 \pm 4.60 \\
p=0.02 v s \text { control }\end{array}$ & $37.55 \pm 3.35$ \\
\hline $\mathrm{VAD}+\mathrm{HF}+\mathrm{RSV}$ & $\begin{aligned} & 34.14 \pm 3.14 \\
p= & 0.008 v s \text { control }\end{aligned}$ & $\begin{aligned} & 26.57 \pm 1.18 \\
p= & 0.002 \text { vs control }\end{aligned}$ & $38.20 \pm 5.40$ \\
\hline
\end{tabular}



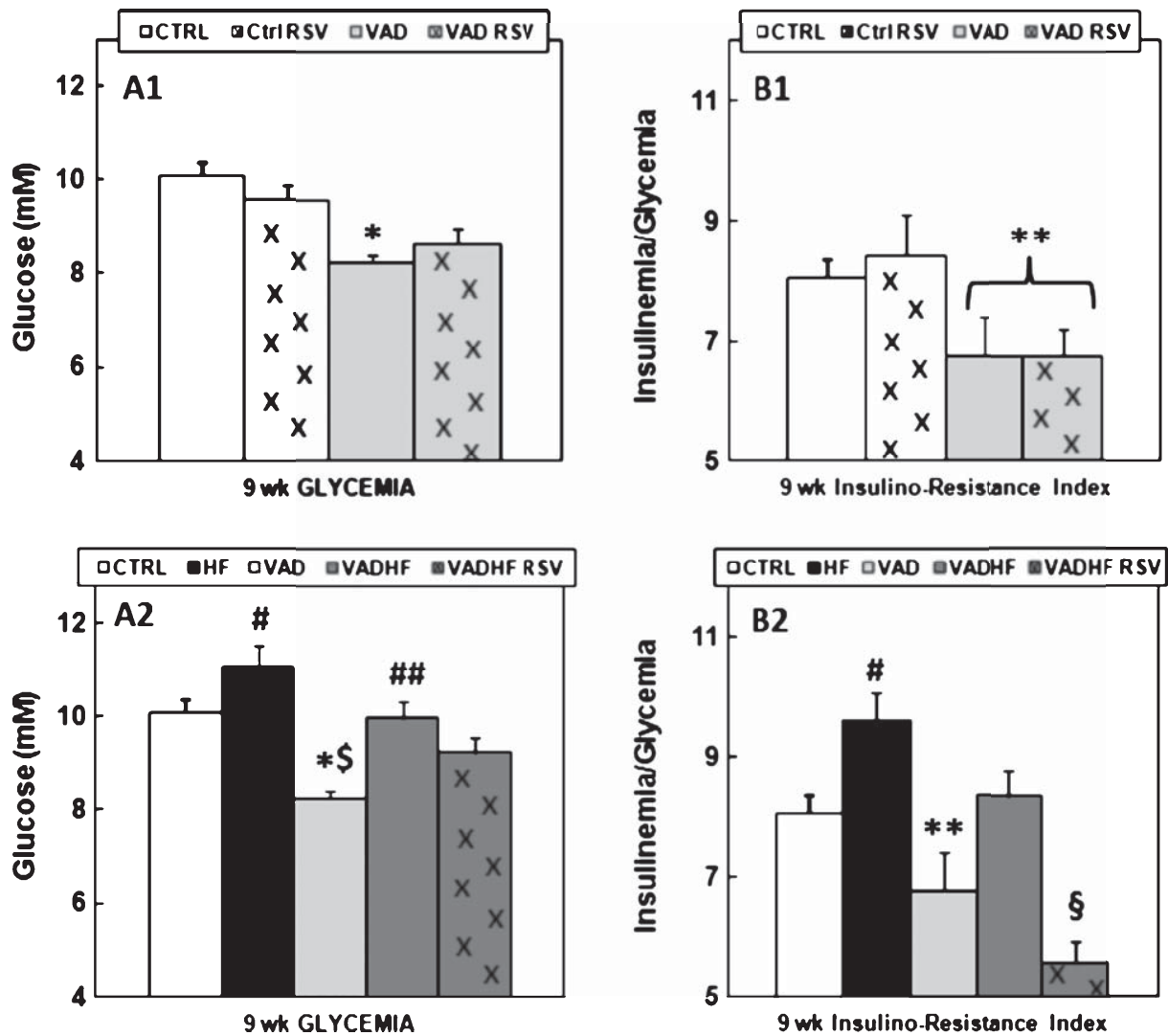

Fig. 3. A1-2: Glycaemia (mmol/L) and B1-2: insulinemia/glycaemia as a marker of insulin resistance, measured at the 9th wk of the diets. $\mathrm{m} \pm \mathrm{SEM}, n=4-5$ in each group and each time. ${ }^{*} p<0.005 v s$ control; $* * p=0.03$ vs control; ${ }^{*} p=0.046 v s$ control and $p=0.0002 v s$ VAD; $\$ p=0.005$ vs VAD + HF; ${ }^{\#} p<0.05$ vs HF.

2-fold at wk 5 ( $p=0.05 v s$ VAD) and 9. Rats receiving $\mathrm{RSV}$ in VAD + HF diets (group 4bis) partially counteracted this latter decrease, with significance at wk 9 $(p=0.012$ vs VAD + HF $)$.

Both VAD and HF diets induced a gradual increase in $\alpha$-tocopherol from wk 5 ( $p=0.02$ and $p=0.03 v s$ controls, respectively). This increase was more marked from the 5th wk in VAD + HF ( $p=0.008 v s$ control $)$ and RSV did not significantly affect this increase.

No significant variation in total cholesterolemia was measured in the majority of diets. At wk 9, it was $1.51 \pm 0.03 \mathrm{mmol} / \mathrm{L}$ in controls, $1.39 \pm 0.14$ in $\mathrm{VAD}, 1.99 \pm 0.34$ in $\mathrm{VAD}+\mathrm{HF}$ and $2.01 \pm 0.10$ in $\mathrm{VAD}+\mathrm{HF}+\mathrm{RSV}$. In HF, cholesterol was higher than in controls at wk $9(2.16 \pm 0.10 \mathrm{mmol} / \mathrm{L}, p=0.01)$.

Protidemia remained unchanged around $55 \mathrm{~g} / \mathrm{L}$ whatever the diet and time of measurement, as did albuminemia, a marker of denutrition, whose values at wk 9 post-weaning were as follows: $26.7 \pm 0.1 \mathrm{~g} / \mathrm{L}$ in controls, $28.3 \pm 0.9 \mathrm{~g} / \mathrm{L}$ in $\mathrm{VAD}, 26.5 \pm 1.7 \mathrm{~g} / \mathrm{L}$ in $\mathrm{HF}, 28.7 \pm 3.5 \mathrm{~g} / \mathrm{L}$ in $\mathrm{VAD}+\mathrm{HF}$ and $27.2 \pm 0.9 \mathrm{~g} / \mathrm{L}$ in $\mathrm{RSV}+\mathrm{VAD}+\mathrm{HF}$.

\subsection{Markers of insulin resistance}

\subsubsection{Insulin/glucose ratio}

IR was assessed by using the blood ratio insulinemia/glycemia. VAD diet (group 2) significantly reduced both glycemia (Fig. 3A1) and the IR index (Fig. 3B1). In contrast, HF diet (group 3) increased gradually IR index between wk 5 and 9; the higher level of insulin $v s$ control was not sufficient to maintain glycemia at the control value $(p=0.046 v s$ control, Fig. 3A2), the IR index being significantly higher $(p=0.05)$ (Fig. 3B2). In VAD + HF (group 4) compared to controls, no change was observed at wk 9 whereas glycemia was higher compared to VAD (Fig. 3B1). Note that at wk 12, the IR index in VAD + HF was 


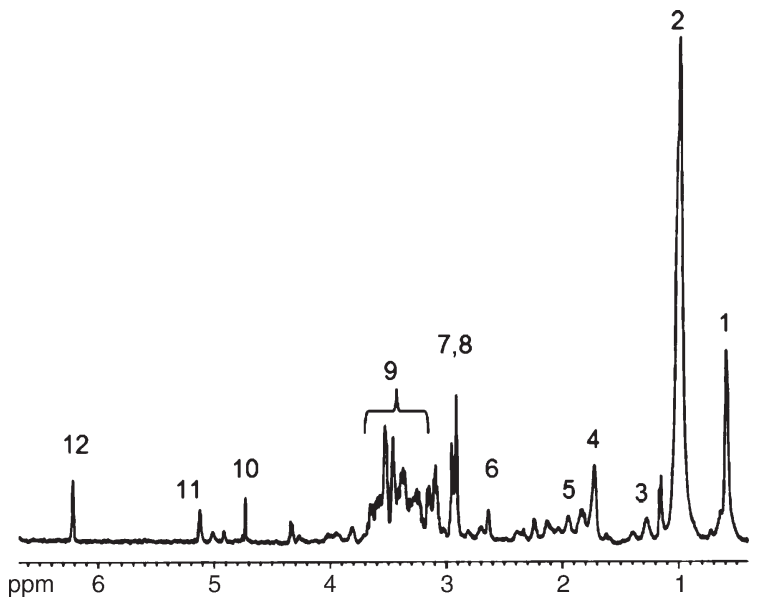

Fig. 4. Typical ${ }^{1} \mathrm{H}$ HRMAS spectrum obtained on a $20 \mathrm{mg}$ liver piece in a control rat. The peak assignments are as follows: Lipids from 1 to 6:1. $\mathrm{CH}_{3}-\left(\mathrm{CH}_{2}\right) \mathrm{n}-; 2$. $\mathrm{CH}_{3}-\left(\mathrm{CH}_{2}\right) \mathrm{n}-; 3 .-\mathrm{CH}_{2}-\mathrm{CH}_{2}-\mathrm{C}=\mathrm{O} ; 4$. $-\mathrm{CH}_{2}-\mathrm{CH}=\mathrm{CH}-; 5 .-\mathrm{CH}_{2}-\mathrm{CH}_{2}-\mathrm{CH}=; 6 .=\mathrm{CH}-\mathrm{CH}_{2}-\mathrm{CH}=$; 7 . glycerophosphorylcholine $\mathrm{R}_{1}-\mathrm{N}^{+}\left(\mathrm{CH}_{3}\right)_{3} ; 8$. choline + phosphocholine $\mathrm{R}_{2}-\mathrm{N}^{+}\left(\mathrm{CH}_{3}\right) 3$; 9. glucose/glycogen $\mathrm{C}_{2} \mathrm{H}, \mathrm{C}_{3} \mathrm{H} ; 10 . \mathrm{H}_{2} \mathrm{O}$ partially saturated; 11. glycogen $\mathrm{C}_{1} \mathrm{H} ; 12$. Fumarate (disodium salt) was used as an external reference to calibrate the spectrum (singlet at $6.5 \mathrm{ppm}$ ).

significantly higher than at wk $9(p=0.03$, not shown). Nutritional intake of RSV in VAD + HF improved insulin sensitivity in VAD (group 2bis, not shown) and in VAD + HF (group 4bis, at wk 9), with a similar glycemia to that in control (Fig. 3A2) but a strong decrease in the IR index $(p=0.004 v s \mathrm{VAD}+\mathrm{HF})$ (Fig. 3B2).

\subsubsection{Liver histology}

The images show a substantial increase in fat accumulation in HF rats compared to control rats at wk 9. Many hepatocytes display a macro- and microvesicular steatosis. Analysis of microvesicular steatosis alone was more difficult to interpret. Some inflammatory infiltrated cells were found (Fig. 2).

\subsection{3. ${ }^{1} \mathrm{H}$ HRMAS liver free fatty acids and blood triglycerides}

A typical spectrum is presented in Fig. 4. The metabolic data mainly concerned free fatty acids (FFA), i.e., absolute quantity and indexes of chain length and unsaturation degree. HF diet (group 3) induced a $\left[-\mathrm{CH}_{3}\right]$ increase (indicating an increase in FFA content) from wk 5 ( $P=0.04 v s$ control) that was more marked at wk 9 ( $p=0.05 v s$ HF 5 wk) (Fig. 5A). No significant change in chain length or saturation
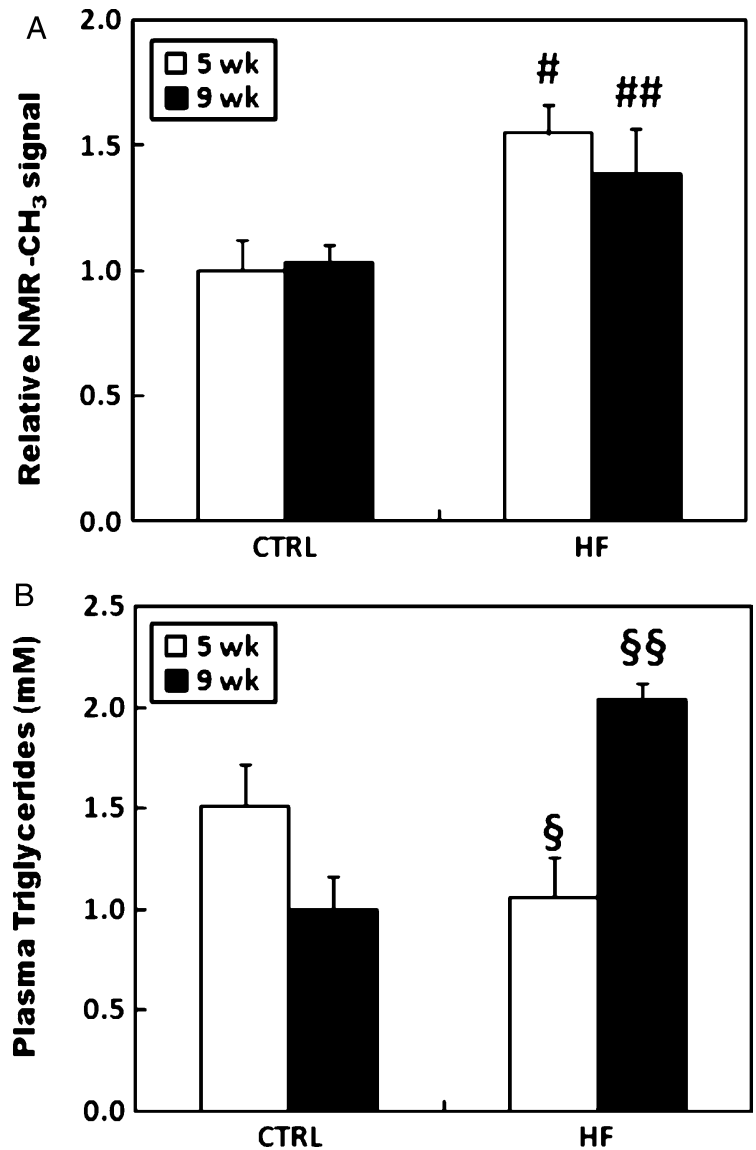

Fig. 5. Effect high-fructose diet (group 3) on (A) liver fatty acid content measured by ${ }^{1} \mathrm{H}$ HRMAS and (B) blood triglycerides ( $\mathrm{mmol} / \mathrm{L}$ ), at wk 5 and 9 following onset of feeding. $\mathrm{m} \pm \mathrm{SEM}, n=4$ in each group and each time. ${ }^{\#} p=0.04 v s$ control $5 \mathrm{wk},{ }^{\# \#} p=0.05 v s$ control $9 \mathrm{wk},{ }^{\S} p=0.05$ vs control $5 \mathrm{wk},{ }^{\S} \S_{p}=0.05$ vs HF $9 \mathrm{wk}$.

degree was noted (data not shown). Blood triglycerides were higher in the HF group at wk $9(p=0.05 v s$ control) (Fig. 5B).

\subsection{Longitudinal in vivo brain anatomic MRI}

Only control and HF rats (groups 1 and 3) were studied for 20 weeks owing to the worse health of VAD rats (groups 2 and 4), which survived a maximum of 15 wks. Like body weight, total cerebral volume progressively increased in the control rats as previously published [5] and in HF rats. In VAD alone, the same authors described a brain volume decrease at wk 9 and 10 of deprivation time as in the present study, whereas it remained similar in controls and HF. We found a 

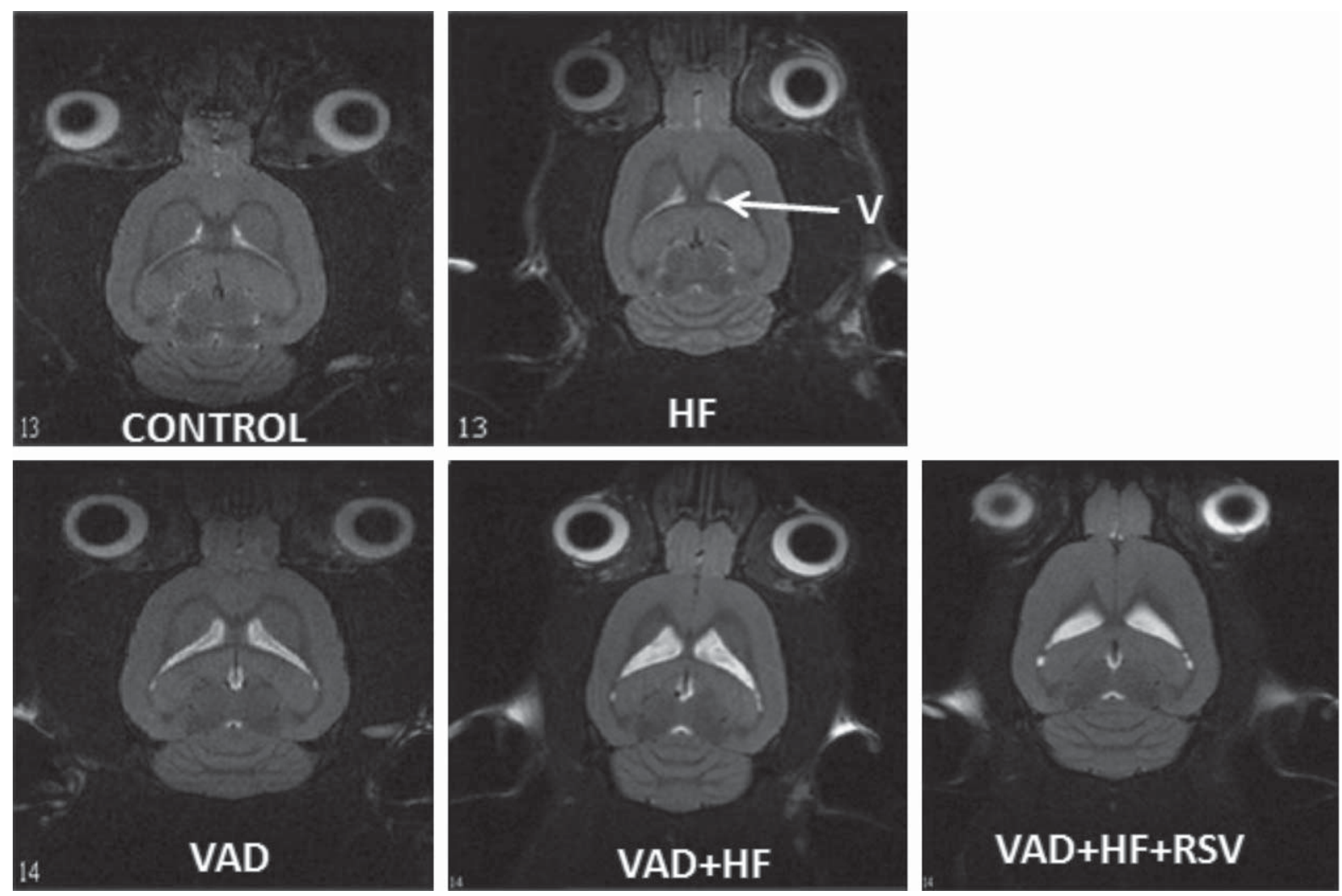

Fig. 6. Typical pictures obtained by in vivo MRI of coronal brain slices according to different diets after 9 weeks of feeding. Each picture corresponds to the same slice. Ventricular spaces (V) are indicated by arrow. Field of view: $1.8 \mathrm{~cm} \times 1.8 \mathrm{~cm}$.

slow gradual increase in ventricular volumes in both Control and HF groups (Fig. 6) linked more probably to aging [33] rather than to the diet (personal data at $15 \mathrm{wk}$ in control, at $14 \mathrm{k}$ and $19 \mathrm{wk}$ in HF with values similar to that shown at $9 \mathrm{wk}$ ). From wk 5 , the hippocampal volume remained stable in both control and HF (not shown). The rapid (from $4 \mathrm{wk}$ ) ventricular increase in VAD $v s$ control confirmed and provided more precision to our previous results.

The main result was obtained in the group with both neurodegeneration and IR (group 4): a large increase in ventricular volume was observed in $\mathrm{VAD}+\mathrm{HF}$ at wk 9 (Figs. 6-7A) ( $p=0.02 v s$ control, $p=0.047 v s$ VAD and $p=0.01 v s \mathrm{HF})$. Moreover, $\mathrm{VAD}+\mathrm{HF}$ decreased the hippocampal volume compared both to VAD alone $(p=0.05)$ or to HF alone $(p=0.001)$ (Fig. 7B).

Owing to the large anatomical impairments observed in VAD and in VAD + HF rats compared to $\mathrm{HF}$ alone ones, the priority was to test the effects of RSV supply in altered situations rather than in HF alone. In fact, it seemed that in absence of an impaired situation, RSV supply induced fewer changes. For instance, RSV improves overall survival in obese mice but, unlike caloric restriction, does not extend lifespan in lean mice [34]. VAD rats receiving RSV (group 1b) stabilized their ventricular volume increase due to VAD, with a volume similar at 15 wks vs 9 wks when compared to VAD alone. When RSV was given in VAD + HF rats (group 4b), it more rapidly counteracted some of the effects of VAD $+\mathrm{HF}$ with a 2-fold lower ventricular volume $(p=0.04)$ (Figs. 6-7A) and a higher hippocampus volume (Fig. 7B) $(p=0.004)$, which was thus similar to control.

\subsection{In vivo brain diffusion tensor imaging}

These preliminary results concerning fractional anisotropy (FA) and mean diffusivity (MD) are presented only in the model known to induce by itself a neurodegenerative process (VAD, group 2). Further experiments will be performed in other experimental 

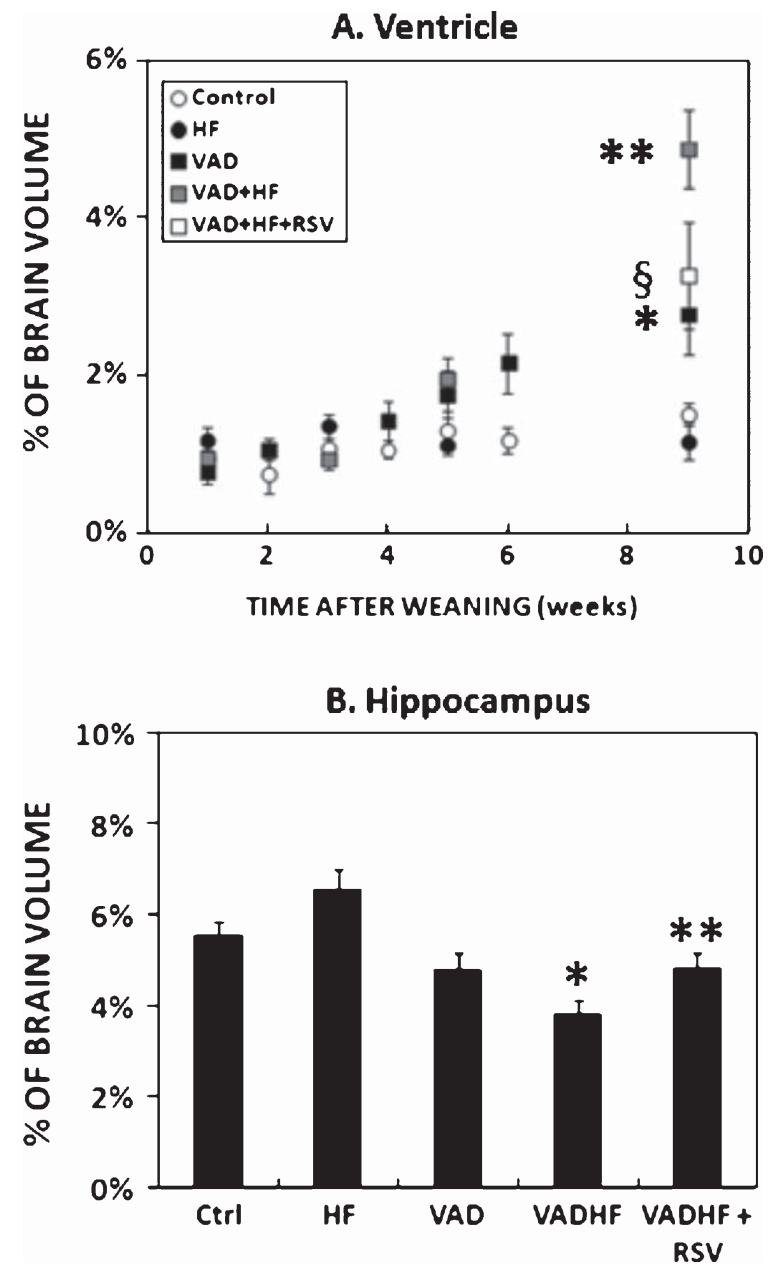

Fig. 7. Ventricular volume (A) during first part of protocol and (B) hippocampal volume at the 9 th week, both expressed as percent of total brain volume $\left(\mathrm{mm}^{3}\right) . \mathrm{m} \pm$ SEM. $n=4-5$. In ventricle at wk 9, $* p=0.05$ vs control, $* * p=0.02$ vs control, $p=0.047$ vs VAD and $p=0.01$ vs HF, ${ }^{\circledR} p=0.04$ vs VAD $+\mathrm{HF}$. In hippocampus, $* p=0.002$ vs control (Ctrl), $p=0.001$ vs $\mathrm{HF}$ and $p=0.05$ vs $\mathrm{VAD}, * * p=0.04$ $v s \mathrm{VAD}+\mathrm{HF}$.

groups. The period of interest was the first 6 wks of VAD in order to detect the earliest diffusivity changes induced by the diet that could occur before metabolic or anatomical impairments. A typical axial T2-weighted image representing the hippocampus ROI is shown in Fig. 8A. For each rat, this image was systematically acquired before DTI sequence to perform an anatomical location in the same spatial axis. The longitudinal study in controls showed an allometric increase in hippocampus FA that was significantly higher at wk 6 than at wk $2(p=0.0035)$. An increase was also found
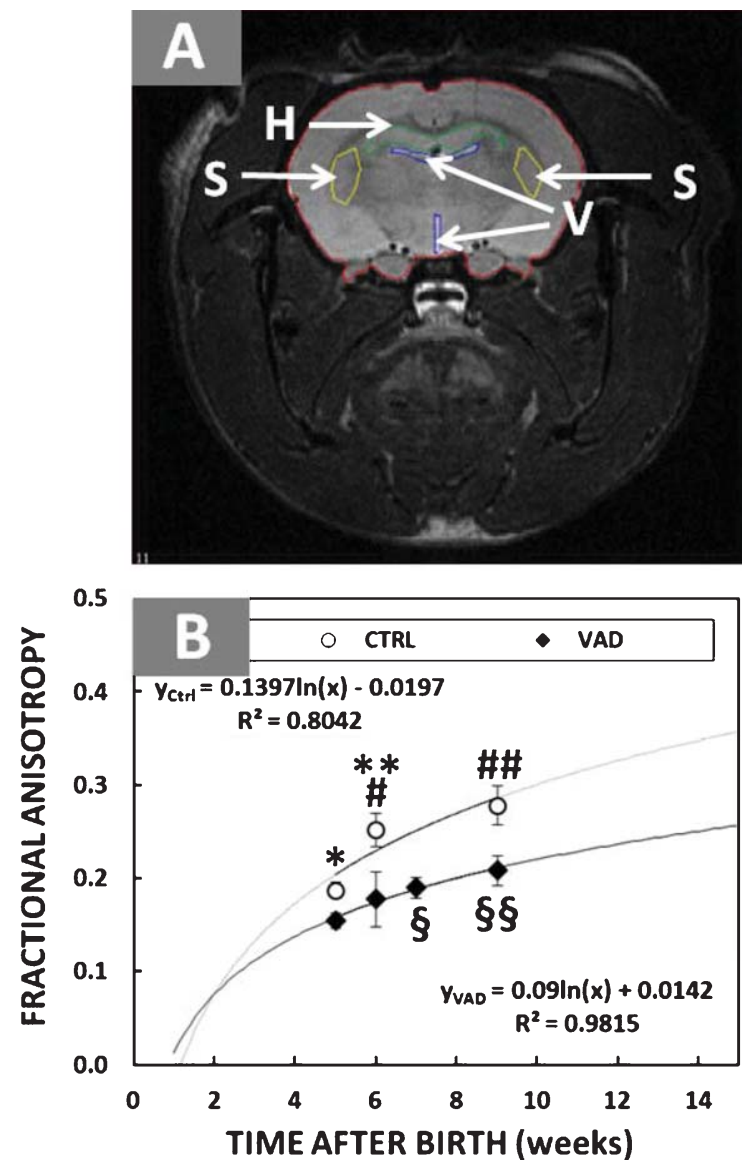

Fig. 8. DTI MRI in VAD (group 2) compared to control (group 1). (A) T2-weighted axial image obtained on a control rat, $\mathrm{H}=$ hippocampus, $\mathrm{V}=$ ventricle, $\mathrm{S}=$ striatum. This anatomical MRI was performed for each rat just before DTI sequence in order to control location of structures; (B) Longitudinal effect of VAD diet on hippocampal fractional anisotropy (FA) of rats. $n=4$ in each group and each time. $\mathrm{m} \pm \mathrm{SEM}$. For the same time: ${ }^{*} p=0.024$ and $*^{*} p=0.042$ control $v s$ VAD. For time-effect: ${ }^{*} p=0.0055$ in control 3 wks post-weaning (PW) (corresponding to $6 \mathrm{wks}$ after birth) $v s$ control 2 wks PW (5 wks after birth) and ${ }^{\# \#} p=0.0035$ in control 6 wks PW (9 wks after birth) $v s$ control 2 wks PW; $\oint^{\oint} p=0.031$ in VAD 4 wks PW (7 wks after birth) $v s$ VAD 2 wks PW and $\oint p=0.012$ in VAD 6 wks PW vs VAD 2 wks PW. The curve's fit extrapolated from birth led to a FA value with a crossover at 2 wks.

in VAD group during rat growth. Both results are in agreement with the recent report of an increase in FA from newborn to adolescence [35]. However, a clear difference between the groups was obtained, with FA values being systematically lower in VAD rats compared to control $(p=0.024$ at wk 2) (Fig. $8 \mathrm{~B})$. The curve's fit led to a calculated value $(\mathrm{FA}=0.085)$ with a crossover at $0.45 \mathrm{wk}$. From this FA value, the difference 


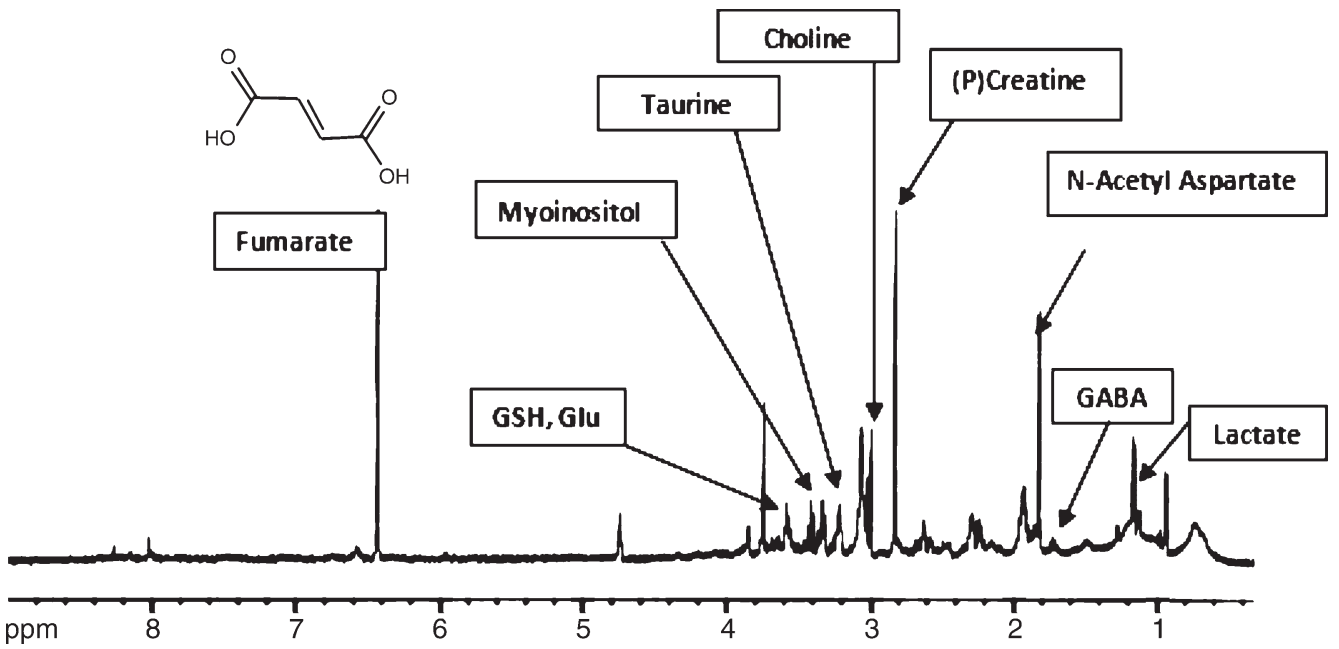

Fig. 9. Typical ${ }^{1} \mathrm{H}$ HRMAS spectrum obtained on $20 \mathrm{mg}$ cortex in a control rat with a CPMG sequence. Results are expressed as the ratio of the intensity of metabolites resonance on intensity of fumarate resonance, corrected by sample weight.
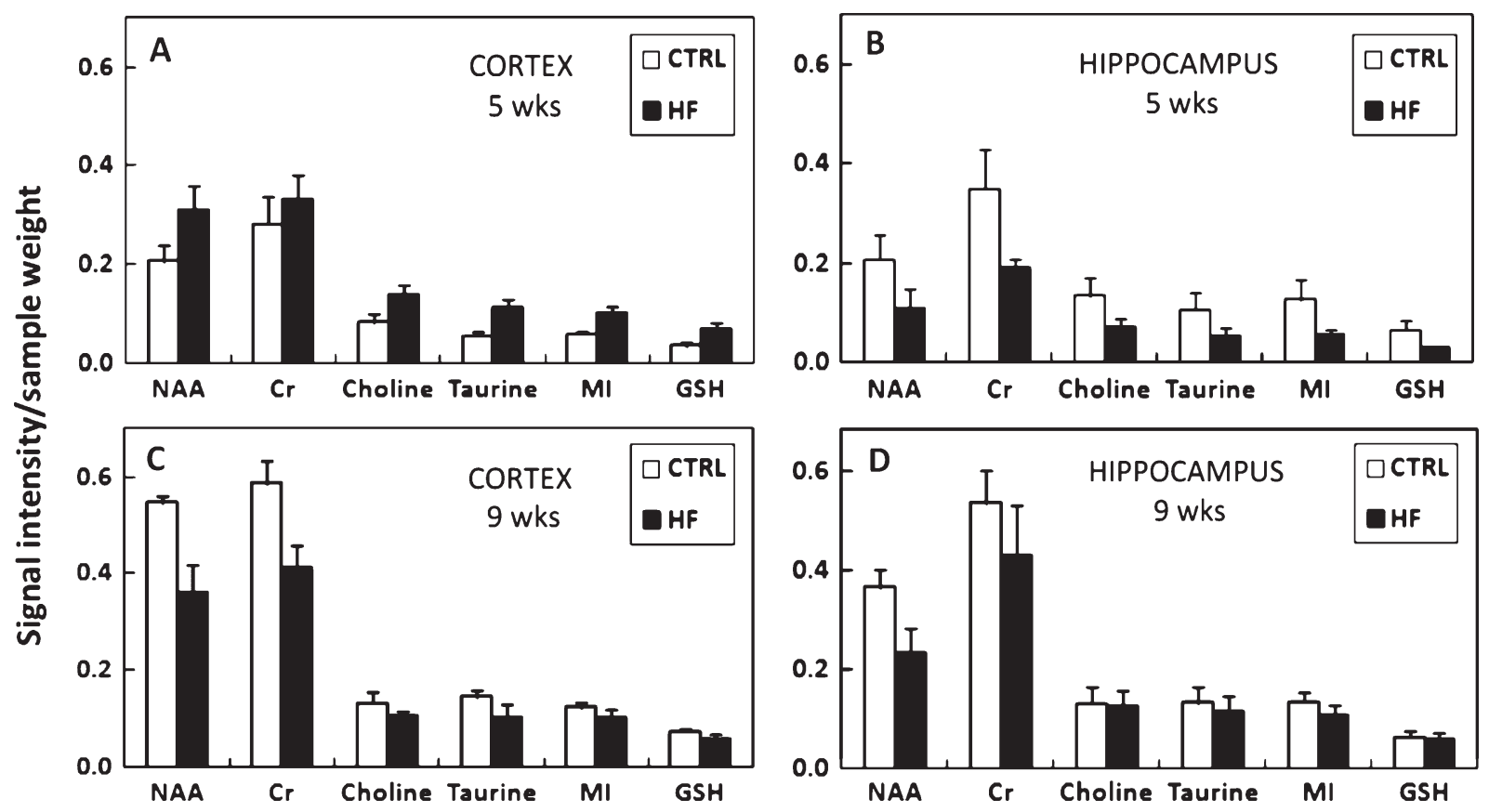

Fig. 10. Effect of fructose diet (group 3) on cortical and hippocampal metabolites measured by ${ }^{1} \mathrm{H}$ HRMAS at the 5th (A-B) and 9th (C-D) week of diet. $\mathrm{m} \pm \mathrm{SEM}, n=4-5$ in each group for each time. $\mathrm{Cr}=$ creatine-phosphocreatine, $\mathrm{MI}=$ myo-inositol, $\mathrm{GSH}=\mathrm{GSH}+\mathrm{GSSG}$.

between the groups increased. In contrast, MD values remained unchanged whatever the group and the duration of the diet. At wk 2, control $=0.98 \pm 0.02 \mathrm{~mm}^{2} / \mathrm{s}$ and $\mathrm{VAD}=0.98 \pm 0.04 \mathrm{~mm}^{2} / \mathrm{s}$; at wk 6 , control $=0.99$ $\pm 0.08 \mathrm{~mm}^{2} / \mathrm{s}$ and $\mathrm{VAD}=1.05 \pm 0.10 \mathrm{~mm}^{2} / \mathrm{s}$.

\section{6. ${ }^{1}$ H HRMAS brain metabolites}

Owing to the absence of HF effect on brain morphology, this part of the study focused on potential distinct effects of fructose on brain metabolites (group 3). 
We previously reported early metabolic impairments linked to VAD alone in differentiated brain structures $[5,6]$. Thus, our hypothesis was that the HF diet could also induce metabolic changes before anatomical ones.

A typical NMR spectrum obtained within 6 min in rat cortex is shown in Fig. 9. In cortex, numerous metabolites increased progressively with rat growth throughout the protocol especially in control but also in HF group. It was significant for some of them such as $\mathrm{N}$-acetyl-aspartate (NAA) ( $p=0.001$ wks $14 v s$ wks $5)$. Early changes due to fructose were measured in both cortex and hippocampus but the profiles were different. Globally, at wk 9, the metabolite increase tended to be systematically lesser in HF rats compared to controls for both cortex (Fig. 10C) and hippocampus (Fig. 10D) and for NAA, creatine, taurine, myoinositol (MI) and glutathione (GSH+GSSG). Concerning wk 5, the decreasing effect of HF on metabolites content was already observed in hippocampus (Fig. 10B), whereas in cortex, fructose first induced at this time an increase in all metabolites (Fig. 10A).

The effects of RSV supply seemed to be linked to the degree of impairment. At the 15th wk postweaning, the NAA/Cr ratio was significantly higher $(p=0.004)$ in the striatum of VAD-RSV rats (group 2bis) vs VAD alone (group 2). In contrast, the RSV supply of VAD + HF (group 4bis) did not significantly change any brain metabolites compared to VAD $+\mathrm{HF}$ alone (group 4).

\section{Discussion}

In recent years, the CNS has emerged as a new site of insulin action. This notion is supported by animal studies based on intracerebroventricular insulin infusion and by experiments in humans that make use of the intranasal pathway of insulin administration to the brain $[36,37]$.

One of the problems in human clinical studies of diabetes and ND is that measurements of glucose metabolism and insulin levels at the time of death in a ND patient are not reflective of the pathological mechanisms that lead to this stage. It is noteworthy that IR may be manifested only by mild glucose intolerance for many years prior to the onset of full-blown T2DM. During these years of metabolic syndrome in which IR is the primum movens, progressive metabolic and/or functional impairments affect the brain. In this context, entirely nutritional models (unlike transgenic models) are of interest because they make it possible the study of the sequence of events following the onset of the process. With the nutritional ND model (vitamin A-free diet), it was thus possible to examine the consequences of induced IR and the putative preventive effect of RSV.

\subsection{Model of neurodegeneration}

We previously validated the VAD rat model by MRI, NMR spectroscopy and gene expression and evidenced a progressive ND process [5, 6]. The present work reports complementary results in VAD (group 2) concerning IR.

The low IR index indicated better insulin sensitivity, in agreement with the reduction in diabetes in vitamin A-deprived diabetic-prone rats. This suggests the role of retinoic acid in the prevention of pancreatic dysfunction [38]. Recent data [39] demonstrate that the retinoid $\mathrm{X}$ receptors (RXRs) inhibit insulin secretion from $\beta$-cells at high glucose levels, this endogenous negative regulation supporting absence of IR in VAD rats. Furthermore, a link has been established in humans between T2DM, IR and serum retinol-binding protein 4 (RBP4), the vitamin A-transport protein secreted into the circulation by adipocytes [40]. An increase in serum RBP4 impairs glucose tolerance because a high level interrupts insulin signaling in muscle and increases hepatic glucose output resulting from elevated neoglucogenesis [41]. So the ND process is thus independent of any IR mechanism in VAD: that's allowed to study the additional effects of inducted IR, without any bias.

\subsection{Model of insulin resistance}

The present IR model used a higher refined carbohydrate content ( $60 \%$ of energy) than in a typical human western diet (8-20\% of energy), so the relevance to humans can be questioned. In fact, Huang et al. [42] obtained the same impairment in the levels of key enzymes involved in FFA synthesis by using $60 \%$ fructose in in vivo studies and $0.5 \mathrm{mmol} / \mathrm{L}$ fructose in in vitro studies, the latter being near a $15-20 \%$ diet.

The present $60 \%$ HF diet induced signs of metabolic syndrome in rats. The increase in both abdominal adiposity and epididymal volumes has been previously reported [43, 44]. Significant IR appeared around wk 9, which is later than in adult HF Wistar rats, but the VAD 
model requires using just-weaning rats, which have no liver retinol stores. Young rats are known to develop IR more slowly [45]. Insulinemia changes were only linked to the diet, Wistar rats being reported to have stable insulinemia between 1 and 12 months [46].

Liver histology demonstrated marked micro- and macrosteatosis and lobular inflammation, as in previous reports $[47,48]$. In agreement with histological observations, an increase in terminal liver FA methyl content was depicted by ${ }^{1} \mathrm{H}$ HRMAS, this metabolic approach being applied for the first time to study liver fatty acids in this diet.

Surprisingly, fructose induced an early increase in blood $\alpha$-tocopherol (antioxidant) that preceded IR, whereas decreased levels have been reported in IR [49]. It could be that in the present short-lasting induction of IR in contrast to well-established IR, inflammation linked to fructose first induced an adaptive increase in the anti-oxidant systems. Accordingly, a $60 \%$-fructose diet in hypertensive rats for 13 wks enhanced the total antioxidant capacity of liver in correlation with increased antioxidant enzyme activities and retinol concentrations [50].

Concerning MRI data, high-fructose did not induce any macro anatomical changes in brain until 19 weeks of diet, which is perhaps a relatively short period in terms of IR. In patients with Type 1/2 DM in whom volumetric studies indicated regional abnormalities in both cortical and sub-cortical (e.g., hippocampus, amygdale) brain structures [51], the data were acquired long after the onset of IR. A prolonged IR status is probably also responsible for the significant negative relationship between Homeostasis Model Assessment-IR and right and total hippocampus volume and overall cognitive performance in postmenopausal women at risk for AD without T2DM [52]. In rats having a high-fat, high-glucose diet supplemented with $20 \%$ high-fructose, 8 months were also necessary to reduce hippocampus dendrite spine density and exhibit impaired spatial learning ability [19].

In contrast to the absence of anatomical changes, early modifications were measured in the metabolic profile by spectroscopic NMR, mainly in the cortex, and to a lesser extent in the hippocampus, which is devoted to cognition. They were already present at wk 9 concomitant with the establishment of a blood IR, pointing to the onset of very early metabolic impairments due to fructose consumption and perhaps correlative to low-grade inflammation. This underlines probable diminished performances in brain functions due to these metabolites. Since NAA has a neuronal location [53], its lesser increase during rat growth in HF compared to controls could reflect a loss in neuronal health, its decrease being largely associated with ND diseases [54]. Furthermore, in vivo NMR-measured frontal-cortical NAA/Creatine and Choline/Creatine ratios were decreased in diabetic patients with poor glycemic control (necessarily IR) [55]. The HF rats also had a lower content in choline, an essential nutrient required for the synthesis of the neurotransmitter acetylcholine and for phosphatidylcholine, a major constituent of membranes. Finally, a lower creatine content in the HF group could also be detrimental owing to its large role in CNS, not only in energy for ATP regeneration and buffering but also for recently suggested functions such as a neurotransmitter or osmolyte [56].

The association of both anatomical and metabolic results was thus very informative and led us to suspect a cascade of events in which the anatomical changes, and certainly further associated cognitive ones, are very late steps compared to the metabolic modifications. In cognitively normal adults, metabolic syndrome has thus been related to cerebral metabolic disturbances, a possible indication of early brain vulnerability [57].

\subsection{Effect of insulin resistance on the neurodegenerative process in VAD rats}

The main result concerning the $\mathrm{VAD}+\mathrm{HF}$ rats (group 4) was firstly the large impairment in general health and body weight curve with a reduced life-span compared to VAD alone. Because VAD and VAD + HF had the same food intake, the higher weight loss in $\mathrm{VAD}+\mathrm{HF}$ for the same energy intake indicated a different nutrient use.

Second, this diet induced a large increase in ventricular volume as measured by MRI, coupled with a decrease in hippocampus volume. Ventricular enlargement is associated with mild cognitive impairment and ND [58]. The hippocampus plays a central role in memory formation, so its atrophy may be the best predictor of progression to ND [59]. Whereas we observed no anatomical change in $\mathrm{HF}$ alone after 20 wks of diet, the IR status enhanced a concomitant ND process from wk 9, thereby providing an answer to the initial question of the effect of IR on the ND process. VAD + HF also induced early metabolic disturbances (present on 
a similar scale to HF alone, data not shown), again evidencing the sequence of metabolic impairments followed by anatomical ones.

Finally, it was unexpected that the combined $\mathrm{VAD}+\mathrm{HF}$ diet largely enhanced the decrease in retinolemia compared to VAD alone. This was significant from wk 5, an early moment where rats presented no systemic IR. This drop in retinol might explain the anatomic impairments linked to the known involvement of retinol in morphogenesis. This original result provides an additional argument for a connection between retinoids and insulin signaling pathways.

\subsection{Effects of resveratrol}

A systematic review of 28 studies suggests that consuming additional polyphenols in the diet can lead to cognitive benefits, although the effects may differ depending on the polyphenol source. Comparison between studies can be hampered by methodological inconsistencies [60]. There have also been differences between in vitro and in vivo experiments [61]. Athar et al. [62] summarize the wide range of concentrations used in vivo from $100 \mathrm{ng}$ to $3,000 \mathrm{mg} / \mathrm{kg} \cdot \mathrm{d}^{-1}$ for animal studies (for a $70 \mathrm{~kg}$ man, equal to $21 \mathrm{~g}$ per day or...91,000 standard glasses of red wine).

In fact the dose is important. In the present in vivo study, rats were force-fed with a concentration of transRSV corresponding to a daily supply of $0.15 \mathrm{mg} / \mathrm{kg}$. That represents daily consumption of red wine around $10.5 \mathrm{mg}$ for a $70 \mathrm{~kg}$ man. According to the grape variety [63], a mean consumption of three standard red wine glasses corresponds in adult human to a daily supply of $0.71 \mathrm{mg}$. Thus our protocol was performed with nearly a 15 -fold higher concentration than a mean consumption of 3 standard glasses of red wine.

In VAD rats, RSV supply (group 1bis) improved some of their impairments. RSV tended to increase life span after 9 wks of feeding. At the 15th wk postweaning, the higher NAA/Cr ratio compared to VAD alone (group 1) suggested an improvement in neuronal health. Finally, VAD rats receiving RSV seemed to stabilize their ventricular volume increase resulting from VAD, but only in the last period of feeding near 15 wks, no difference being observed at 9 wks.

What about the effect of RSV in VAD + HF rats? In this situation (group 4bis), RSV was unable to prevent dramatic weight loss, did not improve life span and induced no improvement in brain metabolic profiles. However, RSV largely restored insulin sensitivity. RSV increases insulin sensitivity of cultured adipocytes [64] and ob/ob mice treated during 4 wks presented a decrease in glycemia and an improvement in insulin levels [65]. Furthermore, in peripheral blood mononuclear cells in vivo, IR and metabolic syndrome were associated with low sirtuines 1 (SIRT1) gene and protein expression [66]. SIRT1 is an $\mathrm{NAD}^{+}$dependent histone deacetylase that is known to be activated by RSV.

Moreover, the large ventricular increase induced by $\mathrm{VAD}+\mathrm{HF}$ (group 4) was partly prevented by RSV (group 4bis), which restored the value close to that of VAD alone at 9 wks and tended also to counterbalance the hippocampal volume decrease. In a model of traumatic brain injury, an intraperitoneal injection of RSV at $100 \mathrm{mg} / \mathrm{kg}$ body weight provided behavioral protection and a reduction in hippocampus loss [67]. Another study points out the role of SIRT1 activation in the development and maintenance of dendritic branching in hippocampal neurons [68].

A surprising result in VAD + HF rats supplemented with RSV (group 4bis) is the maintenance of blood retinol at a level superior to that obtained with $\mathrm{VAD}+\mathrm{HF}$ alone, so retinol, which is involved in morphogenesis, may partly explain this anatomical improvement. This role of RSV on retinol level was unexpected and could be due to its insulin-sensitive effect, thus acting on the relationship between insulin and retinoid signaling pathways. Donmez et al. [69] demonstrated that SIRT1 directly activates the transcription of the gene encoding the alpha-secretase, ADAM10. SIRT1 deacetylates and coactivates the RAR $\beta$, a known regulator of ADAM10 transcription. The alpha-secretase allows protein amyloid precursor protein cleavage and avoids the production of $\mathrm{A} \beta$ peptides.

On the other hand, RSV could compensate the dysregulation of oxidative phosphorylation due to vitamin A deprivation, owing to its involvement in energy metabolism. In fact, retinol has been demonstrated to participate in mitochondrial energy homeostasis by enhancing the flux of pyruvate into the Krebs cycle [70]. The most probable energetic target of RSV is the AMP-activated protein kinase (AMPK). AMPK is a sensor and regulator of cellular energy metabolism. Emerging evidence demonstrates that AMPK activation is a potential target for improving the perturbed brain energy metabolism that is involved in the pathogenesis of AD [71]. Orally administered RSV in mice 
was detected in the brain where it promoted AMPK activation by the calcium/calmodulin-dependent protein kinase kinase-beta and reduced cerebral ßamyloid protein levels and deposition in the cortex [29]. In fact, SIRT1 and AMPK are closely linked, SIRT1 playing an essential role in the ability of moderate doses of RSV to stimulate AMPK and improve mitochondrial function both in vitro and in vivo [72].

Finally, we hypothesize that besides its involvement in energy metabolism, the largely debated antioxidant properties of RSV are not its main effect here owing to the concentration used.

\subsection{Perspectives}

The ultimate goal could be to have a very early diagnostic tool. DTI is the only non-invasive method for characterizing the microstructural organization of pathological or normal-appearing tissue in vivo. It is an NMR imaging technique that exploits the exquisite sensitivity of MR imaging to diffusion processes in water to measure in vivo microscopic tissue orientation characteristics. The FA metric provides a simple and robust means to assess the degree of anisotropic diffusion occurring within a region. FA is high in regions of high organization, intermediate in regions with some degree of organization and low in water tissues where the predominant cell shape, and therefore diffusion, is not specifically oriented (e.g., grey matter) [73]. The interest of DTI will be to detect changes at the earliest possible step by using new sequences and post-processing 3D schema [74, 75]. DTI has been applied in a wide range of neurologic areas, and in aging research. In this study, we evidence an increase in the hippocampus FA during growth. Moreover, we obtained lower FA values in the hippocampus of VAD rats $v s$ controls, in agreement with those measured with advancing age [76], mild cognitive impairment [77] and $\mathrm{AD}$ [78]. In this study, some FA changes without MD change could suggest some variations in fibers membranes in absence of edema; in fact, MD is an index of global water movement, whereas FA, an index of micro structural integrity of the brain fibers, reflects the diffusion of water molecules along them.

There is now growing evidence that vascular disorders and/or impaired cerebral irrigation contribute to the development of ND [79]. Among the brain metabolic changes induced either by VAD, HF and $\mathrm{VAD}+\mathrm{HF}$ diets, taurine, an abundant amino-acid in the nervous system, was found lower in various proportions compared to controls. Taurine largely participates in cell volume regulation and a striatal decrease has been evidenced in old rats with poor spatial memory in contrast to unimpaired young ones [80]. Taurine can thus provide an interesting link between memory loss and the osmotic brain imbalance observed in the neurodegenerative process; its decrease could be an indicator for further DTI studies.

A "vascular hypothesis" has been put forward for linking metabolic syndrome, IR, and ND [81, 82]. Hemodynamic and metabolic effects working in concert enhance energy substrate delivery [83]. Interestingly, insulin directly affects vasoreactivity and hemodynamic functions. In turn, endothelial dysfunction reduces insulin transport and ultimately micro vascular blood flow.

\section{Conclusion}

The strengths of the present work were (i) the choice of rat nutritional models in which metabolic and neuropathologic disorders appeared gradually, in contrast to transgenic models; and (ii) the investigation of the ND process in VAD rats as a model independent of any IR mechanism, thereby allowing the study of the effects of IR induction without any bias.

The main conclusions are (i) a probable relationship between the retinoid and insulin signaling pathways, since either vitamin A, fructose or RSV largely participate in the energy metabolism, suggesting common metabolic crossroads; (ii) a clear increase in some ND impairments with IR; (iii) some very early changes in brain micro structural organization during ND; and (iv) some beneficial effects of RSV in the context of ND and IR.

All these findings together with previous ones [4-7, 21 ] suggest a cascade of events in the ND process that are potentially enhanced by IR. In order of occurrence, these are: $1 /$ early subtle disturbances in brain water diffusivity, 2/ metabolic brain impairments, 3/ onset of the characteristic anatomical changes, 4/ gene expression impairments concerning synaptic plasticity, and 5/ clinical symptoms affecting cognition and memory. Such a hypothesis cannot be put forward without the combined contribution of data obtained with tools investigating diffusivity, metabolism, anatomy, gene expression and behavioral changes. Such tools are 
essential for providing a very early diagnosis, which is a prerequisite for any prevention strategy.

\section{Acknowledgments}

With Institut de Recherche et d'Etudes sur les Boissons (IREB) grants. The authors are grateful to Bassem Hiba for his contribution to the experiments using DTI method and his participation to some MRI experiments. We thank our engineer Marc Biran for support on NMR techniques. We also thank Ray Cooke for linguistic assistance.

\section{References}

[1] World Alzheimer's Report 2009, Alzheimer's Disease International. www.alz.co.uk/worldreport

[2] Saunders C, Spencer JPE. Metabolic and immune risk factors for dementia and their modifications by flavonoids: New targets for the prevention of cognitive impairment? Nutr Aging. 2012;1:69-88.

[3] Eichenbaum H. The hippocampus and mechanisms of declarative memory. Behav Brain Res. 1999;103(2):122-33.

[4] Ghenimi N, Beauvieux MC, Biran M, Pallet V, Higueret P, Gallis JL. Vitamin A deficiency in rats induces anatomic and metabolic changes comparable with those of neurodegenerative disorders. J Nutr. 2009;139(4):696-702.

[5] Beauvieux MC, Ghenimi Rahab N, Raffard G, Enderlin V, Pallet V, Higueret P, et al. The early decrease in N-Acetyl Aspartate / Glutathione, a brain health marker, induced by Vitamin A deprivation in rat is reversed by retinoic acid. Open Magn Resonance J. 2009;2:71-9.

[6] Cocco S, Diaz G, Stancampiano R, Diana A, Carta M, Curreli $\mathrm{R}$, et al. Vitamin A deficiency produces spatial learning and memory impairment in rats. Neuroscience. 2002;115(2):47582

[7] Corcoran JP, So PL, Maden M. Disruption of the retinoid signaling pathway causes a deposition of amyloid beta in the adult rat brain. Eur J Neurosci. 2004;20:896-902.

[8] Ono K, Yamada M. Vitamin A and Alzheimer's disease. Geriatr Gerontol Int. 2012;12(2):180-8.

[9] Strachan MW, Reynolds RM, Frier BM, Mitchell RJ, Price JF. The relationship between type 2 diabetes and dementia. $\mathrm{Br}$ Med Bull. 2008;88(1):131-46.

[10] Lamport DJ, Hoyle E, Lawton CL, Mansfield MW, Dye L. Evidence for a second meal cognitive effect: Glycaemic responses to high and low glycaemic index evening meals are associated with cognition the following morning. Nutr Neurosc. 2011;14(2):66-71.

[11] Craft S. The role of metabolic disorders in Alzheimer disease and vascular dementia. Arch Neurol. 2009;66(3):300-5.

[12] Raffaitin C, Féart C, Le Goff M, Amieva H, Helmer C, Akbaraly $\mathrm{TN}$, et al. Metabolic syndrome and cognitive decline in French elders: The Three-City Study. Neurology. 2011;76(6): 518-25.
[13] Banks WA, Owen JB, Erickson MA. Insulin in the brain: There and back again. Pharmacol Ther. 2012;136(1):82-93.

[14] Bosco D, Fava A, Plastino M, Montalcini T, Pujia A. Possible implications of insulin resistance and glucose metabolism in Alzheimer's disease pathogenesis. J Cell Mol Med. 2011;15(9):1807-21.

[15] Dou JT, Chen M, Dufour F, Alkon DL, Zhao WQ. Insulin receptor signaling in long-term memory consolidation following spatial learning. Learn Mem. 2005;12(6):646-55.

[16] Lê KA, Tappy L. Metabolic effects of fructose. Metab Care. 2006;9(4):469-75.

[17] Tappy L, Lê KA. Metabolic effects of fructose and the worldwide increase in obesity. Physiol Rev. 2010;90(1):23-46.

[18] Ross AP, Bartness TJ, Mielke JG, Parent MB. A high fructose diet impairs spatial memory in male rats. Neurobiol Learn Mem. 2009;92(3):410-6.

[19] Stranahan AM, Norman ED, Lee K, Cutler RG, Telljohann $\mathrm{R}$, Egan JM, et al. Diet-induced insulin resistance impairs hippocampal synaptic plasticity and cognition in middle-aged rats. Hippocampus. 2008;18(11):1085-88.

[20] Mielke JG, Taghibiglou C, Liu L, Zhang Y, Jia Z, Adeli K, et al. A biochemical and functional characterization of dietinduced brain insulin resistance. J Neurochem. 2005;93(6): 1568-78.

[21] Husson M, Enderlin V, Delacourte A, Ghenimi N, Alfos S, Pallet $\mathrm{V}$, et al. Retinoic acid normalizes nuclear receptor mediated hypo-expression of proteins involved in beta-amyloid deposits in the cerebral cortex of vitamin A deprived rats. Neurobiol Dis. 2006;23(1):1-10.

[22] Bonnet E, Touyarot K, Alfos S, Pallet V, Higueret P, Abrous DN. Retinoic acid restores adult hippocampal neurogenesis and reverses spatial memory deficit in vitamin A deprived rats. PLoS One. 2008;3:e3487.

[23] Gan L. Therapeutic potential of sirtuin-activating compounds in Alzheimer's disease. Drug New Perspect. 2007;20(4):23339.

[24] Sun AY, Wang Q, Simonyi A, Sun GY. Resveratrol as a therapeutic agent for neurodegenerative diseases. Mol Neurobiol. 2010;41(2-3):375-83.

[25] Guarente L. Sirtuins as potential targets for metabolic syndrome. Nature. 2006;444(7121):868-74.

[26] Zabolotny JM, Kim YB. Silencing insulin resistance through SIRT1. Cell Metab. 2007;6(4):307-19.

[27] Ramadori G, Gautron L, Fujikawa T, Vianna CR, Elmquist JK, Coppari R. Central administration of resveratrol improves diet-induced diabetes. Endocrinology. 2009;150(12):532633.

[28] Ates O, Cayli SR, Yucel N, Altinoz E, Kocak A, Durak MA, et al. Central nervous system protection by resveratrol in streptozotocin-induced diabetic rats. J Clin Neurosci. 2007;14(3):256-60.

[29] Vingtdeux V, Giliberto L, Zhao H, Chandakkar P, Wu Q, Simon JE, et al. AMP-activated protein kinase signaling activation by resveratrol modulates amyloid-beta peptide metabolism. J Biol Chem. 2010;285(12):9100-13.

[30] Poole T EP. UFAW guidelines handbook on the care and management of laboratory animals. Terrestrial vertebrates ed Oxford, 1999.

[31] Leclercq M, Bourgeay-Causse M. Une méthode simple fiable et rapide: Dosage simultané du rétinol et du tocophérol sérique 
par chromatographie haute performance. Rev Inst Pasteur Lyon. 1981;14:475-96.

[32] Klein-Szanto AJ, Martin DH, Pine AH. Cutaneous manifestations in rats with advanced vitamin A deficiency. J Cutan Pathol. 1980;7(4):260-70.

[33] Roy M, Nugent S, Tremblay-Mercier J, Tremblay S, Courchesne-Loyer A, Beaudoin JF, et al. The ketogenic diet increases brain glucose and ketone uptake in aged rats: A dual tracer PET and volumetric MRI study. Brain Res. 2012;1488: 14-23.

[34] Agarwal B, Baur JA. Resveratrol and life extension. Ann N Y Acad Sci. 2011;1215:138-43

[35] Yap QJ, Teh I, Fusar-Poli P, Sum MY, Kuswanto C, Sim K. Tracking cerebral white matter changes across the lifespan: Insights from diffusion tensor imaging studies. J Neural Transm. 2013;120(9):1369-95.

[36] Reger MA, Watson GS, Green PS, Wilkinson CW, Baker LD, Cholerton B, et al. Intranasal insulin improves cognition and modulates beta-amyloid in early AD. Neurology. 2008;70(6):440-8.

[37] Ott V, Benedict C, Schultes B, Born J, Hallschmid M. Intranasal administration of insulin to the brain impacts cognitive function and peripheral metabolism. Diabetes Obes Metab. 2012;14(3):214-21. Review

[38] Driscoll HK, Chertow BS, Jelic TM, Baltaro RJ, Chandor SB, Walker EM, et al. Vitamin A status affects the development of diabetes and insulitis in BB rats. Metabolism. 1996;45(2):24853.

[39] Miyazaki S, Taniguchi H, Moritoh Y, Tashiro F, Yamamoto T, Yamato E, et al. Nuclear hormone retinoid X receptor (RXR) negatively regulates the glucose-stimulated insulin secretion of pancreatic B-cells. Diabetes. 2010;59(11):2854-61.

[40] Wolf G. Serum retinol-binding protein: A link between obesity, insulin resistance, and type 2 diabetes. Nutr Rev. 2007;65(5):251-6.

[41] Yang Q, Graham TE, Mody N, Preitner F, Peroni OD, Zabolotny JM, et al. Serum retinol binding protein 4 contributes to insulin resistance in obesity and type 2 diabetes. Nature. 2005;436(7049):356-62.

[42] Huang D, Dhawan T, Young S, Yong WH, Boros LG, Heaney AP. Fructose impairs glucose-induced hepatic triglyceride synthesis. Lipids Health Dis. 2011;10:20.

[43] Kanarek RB, Orthen-Gambill N. Differential effects of sucrose, fructose and glucose on carbohydrate-induced obesity in rats. J Nutr. 1982;112(8):1546-54.

[44] Nseir W, Nassar F, Assy N. Soft drinks consumption and nonalcoholic fatty liver disease. World J Gastroenterol. 2010;16(21):2579-88.

[45] de Moura RF, Ribeiro C, de Oliveira JA, Stevanato E, de Mello MA. Metabolic syndrome signs in Wistar rats submitted to different high-fructose ingestion protocols. Br J Nutr. 2009;101(8):1178-84.

[46] Perrin D. In: Characterisation of energy balance and its central and peripheral monoaminergic control in an obesity-resistant rat (Lou/C rat). Thèse Université Claude Bernard, Lyon, 2003;103:176

[47] Botezelli JD, Cambri LT, Ghezzi AC, Dalia RA, Voltarelli FA, de Mello MA. Fructose-rich diet leads to reduced aerobic capacity and to liver injury in rats. Lipids Health Dis. 2012;11:78. doi: 10.1186/1476-511X-11-78
[48] Kohli R, Kirby M, Xanthakos SA, Softic S, Feldstein AE, Saxena V, et al. High-fructose, medium chain trans fat diet induces liver fibrosis and elevates plasma coenzyme Q9 in a novel murine model of obesity and nonalcoholic steatohepatitis. Hepatology. 2010;52(3):934-44.

[49] Botella-Carretero JI, Balsa JA, Vázquez C, Peromingo R, Díaz-Enriquez M, Escobar-Morreale HF. Retinol and alpha-tocopherol in morbid obesity and nonalcoholic fatty liver disease. Obes Surg. 2010;20(1):69-76.

[50] Girard A, Madani S, Boukortt F, Cherkaoui-Malki M, Belleville J, Prost J. Fructose-enriched diet modifies antioxidant status and lipid metabolism in spontaneously hypertensive rats. Nutrition. 2006;22(7-8):758-66.

[51] McIntyre RS, Kenna HA, Nguyen HT, Law CW, Sultan F, Woldeyohannes HO, et al. Brain volume abnormalities and neurocognitive deficits in diabetes mellitus: Points of pathophysiological commonality with mood disorders? Adv Ther. 2010;27(2):63-80.

[52] Rasgon NL, Kenna HA, Wroolie TE, Kelley R, Silverman D, Brooks J, Williams KE, et al. Insulin resistance and hippocampal volume in women at risk for Alzheimer's disease. Neurobiol Aging. 2011;32(11):1942-8.

[53] Moffett JR, Namboodiri MA, Cangro CB, Neale JH. Immunohistochemical localization of $\mathrm{N}$-acetylaspartate in rat brain. Neuroreport. 1991;2(3):131-4.

[54] Rigotti DJ, Inglese $\mathrm{M}$, Gonen $\mathrm{O}$. Whole-brain $\mathrm{N}$ acetylaspartate as a surrogate marker of neuronal damage in diffuse neurologic disorders. AJNR Am J Neuroradiol. 2007;28(10):1843-9.

[55] Sahin I, Alkan A, Keskin L, Cikim A, Karakas HM, Firat AK, et al. Evaluation of in vivo cerebral metabolism on proton magnetic resonance spectroscopy in patients with impaired glucose tolerance and type 2 diabetes mellitus. J Diabetes Complications. 2008;22(4):254-60.

[56] Braissant O, Henry H, Béard E, Uldry J. Creatine deficiency syndromes and the importance of creatine synthesis in the brain. Amino Acids. 2011;40(5):1315-24.

[57] Haley AP, Gonzales MM, Tarumi T, Miles SC, Goudarzi K, Tanaka H. Elevated cerebral glutamate and myo-inositol levels in cognitively normal middle-aged adults with metabolic syndrome. Metab Brain Dis. 2010;25(4):397-405.

[58] Apostolova LG, Green AE, Babakchanian S, Hwang KS, Chou YY, Toga AW, et al. Hippocampal atrophy and ventricular enlargement in normal aging, mild cognitive impairment (MCI), and Alzheimer Disease. Alzheimer Dis Assoc Disord. 2012;26(1):17-27.

[59] Chetelat G, Baron JC. Early diagnosis of Alzheimer's disease: Contribution of structural neuroimaging. Neuroimage. 2003;18(2):525-41.

[60] Lamport DJ, Dye L, JoLynne D, Wightman JD, Lawton CL. The effects of flavonoid and other polyphenol consumption on cognitive performance: A systematic research review of human experimental and epidemiological studies. Nutr Aging. 2012;1:5-25.

[61] Stakleff KS, Sloan T, Blanco D, Marcanthony S, Booth TD, Bishayee A. Resveratrol exerts differential effects in vitro and in vivo against ovarian cancer cells. Asian Pac J Cancer Prev. 2012;13(4):1333-40.

[62] Athar M, Back JH, Tang X, Kim KH, Kopelovich L, Bickers DR, et al. Resveratrol: A review of preclinical stud- 
ies for human cancer prevention. Toxicol Appl Pharmacol. 2007;224(3):274-83.

[63] Stervbo U, Vang O, Bonnesen C. A review of the content of the putative chemopreventive phytoalexin resveratrol in red wine. Food Chem. 2007;101(2):449-57.

[64] Kang L, Heng W, Yuan A, Baolin L, Fang H. Resveratrol modulates adipokine expression and improves insulin sensitivity in adipocytes: Relative to inhibition of inflammatory responses. Biochimie. 2010;92(7):789-96.

[65] Sharma S, Misra CS, Arumugam S, Roy S, Shah V, Davis JA, et al. Antidiabetic activity of resveratrol, a known SIRT1 activator in a genetic model for type-2 diabetes. Phytother Res. 2011;25(1):67-73.

[66] de Kreutzenberg SV, Ceolotto G, Papparella I, Bortoluzzi A, Semplicini A, Dalla Man C, Cobelli C, et al. Downregulation of the longevity-associated protein sirtuin 1 in insulin resistance and metabolic syndrome: Potential biochemical mechanisms. Diabetes. 2010;59(4):1006-15.

[67] Singleton RH, Yan HQ, Fellows-Mayle W, Dixon CE. Resveratrol attenuates behavioral impairments and reduces cortical and hippocampal loss in a rat controlled cortical impact model of traumatic brain injury. J Neurotrauma. 2010;27(6):1091-9.

[68] Codocedo JF, Allard C, Godoy JA, Varela-Nallar L, Inestrosa NC. SIRT1 regulates dendritic development in hippocampal neurons. PLoS One. 2012;7(10):e47073.

[69] Donmez G, Wang D, Cohen DE, Guarente L, Paul F. SIRT1 suppresses beta-amyloid production by activating the alphasecretase gene ADAM10. Cell. 2010;142(2):320-32.

[70] Acin-Perez R, Hoyos B, Zhao F, Vinogradov V, Fischman DA, Harris RA, et al. Control of oxidative phosphorylation by vita$\min$ A illuminates a fundamental role in mitochondrial energy homoeostasis. FASEB J. 2010;24(2):627-36.

[71] Cai Z, Yan LJ, Li K, Quazi SH, Zhao B. Roles of AMP-activated protein kinase in Alzheimer's disease. Neuromolecular Med. 2012;14(1):1-14.

[72] Price NL, Gomes AP, Ling AJ, Duarte FV, Martin-Montalvo A, North BJ, et al. SIRT1 is required for AMPK activation and the beneficial effects of resveratrol on mitochondrial function. Cell Metab. 2012;15(5):675-90.

[73] Grieve SM, Williams LM, Paul RH, Clark CR, Gordon E. Cognitive aging, executive function, and fractional anisotropy:
A diffusion tensor MR imaging study. Am J Neuroradiol. 2007;28(2):226-35.

[74] Hiba B, Serduc R, Provent P, Farion R, Rémy C, Ziegler A. 2D J-resolved spiral spectroscopic imaging at 7T: Application to mobile lipid mapping in a rat glioma. Magn Reson Med. 2004;52(3):658-62.

[75] Hiba B, Richard N, Thibault H, Janier M. Cardiac and respiratory self-gated cine MRI in the mouse: Comparison between radial and rectilinear techniques at 7T. Magn Reson Med. 2007:58(4):745-53.

[76] Nusbaum AO, Tang CY, Buchsbaum MS, Wei TC, Atlas SW. Regional and global changes in cerebral diffusion with normal aging. Am J Neuroradiol. 2001;22(1):136-42.

[77] Stebbins GT, Murphy CM. Diffusion tensor imaging in Alzheimer's disease and mild cognitive impairment. Behav Neurol. 2009;21(1):39-49.

[78] Hong YJ, Yoon B, Lim SC, Shim YS, Kim JY, Ahn KJ, et al. Microstructural changes in the hippocampus and posterior cingulate in mild cognitive impairment and Alzheimer's disease: A diffusion tensor imaging study. Neurol Sci. 2013;34(7):1215-21.

[79] Qiu C, Xu W, Winblad B, Fratiglioni L. Vascular risk profiles for dementia and Alzheimer's disease in very old people: A population-based longitudinal study. J Alzheimers Dis. 2010;20(1):293-300.

[80] Dawson R, Jr., Pelleymounter MA, Cullen MJ, Gollub M, Liu $\mathrm{S}$. An age-related decline in striatal taurine is correlated with a loss of dopaminergic markers. Brain Res Bull. 1999;48(3):31924.

[81] Milionis HJ, Florentin M, Giannopoulos S. Metabolic syndrome and Alzheimer's disease: A link to a vascular hypothesis? CNS Spectr. 2008;13(7):606-13.

[82] Murray IV, Proza JF, Sohrabji F, Lawler JM. Vascular and metabolic dysfunction in Alzheimer's disease: A review. Exp Biol Med (Maywood). 2011;236(7):772-82.

[83] Cersosimo E, DeFronzo RA. Insulin resistance and endothelial dysfunction: The road map to cardiovascular diseases. Diabetes Metab Res Rev. 2006;22(6):423-36. Review. 